\title{
Research Paper \\ Structural relationship math self-schemas and math affective memories with math enthusiasm: mediating role and task value and ability/expectancy beliefs
}

\footnotetext{
Fakhrisadat Hosseini ${ }^{1}$, Esmaeil Saadipour ${ }^{2}$, Fariborz Dortaj ${ }^{2}$, Siavash Talepasand ${ }^{3}$, Asghar Minai $^{4}$

1. Ph.D Student of Educational Psychology, Faculty of Psychology and Educational Sciences, Allameh Tabataba'i University, Tehran, Iran.

2. Professor, Department of Educational Psychology, Faculty of Psychology and Educational Sciences, Allameh Tabataba'i University, Tehran, Iran.

3. Associate Professor, Department of Educational Psychology, Faculty of Psychology and Educational Sciences, Semnan University University, Semnan, Iran.

4. Associate Professor, Department of Assessment and Measurement, Faculty of Psychology and Educational Sciences, Allameh Tabataba'i University, Tehran, Iran.
}

Citation: Hosseini F, Saadipour E, Dortaj F, Talepasand S, Minai A. Structural relationship math self-schemas and math affective memories with math enthusiasm: mediating role and task value and ability/expectancy beliefs. J of Psychological Science. 2021; 20(105): 1471-1492.

URL: https://psychologicalscience.ir/article-1-955-fa.html
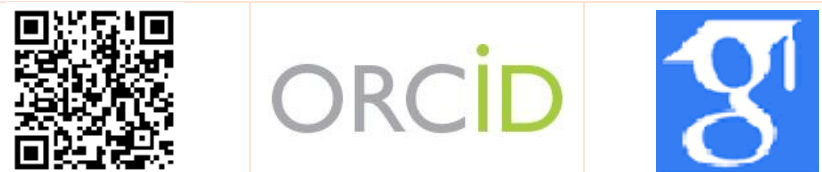

$10.52547 / J P S .20 .105 .1471$

\section{A R T I C L I N F A A B S T R A T}

Keywords:

Math affective memories, Math Enthusiasm

Ability / expectancy beliefs,

Task value,

Math self-schemas

Received: 13 Sep 2020 Accepted: 10 Oct 2020 Available: 22 Nov 2021
Background: Numerous studies have examined academic Enthusiasm. But research on developing a structural model for predicting mathematical enthusiasm based on Math self-schemas and Math Affective Memories mediated by task value and Ability/expectancy Beliefs has been neglected. Aims: The present research aimed to study Structural Relationship between Math affective memories and Math self-schemas with Math Enthusiasm by Mediating Role of Ability/expectancy beliefs and Task.

Methods: This study was a correlational study using structural equation modeling in which500 female students in 11th grade studying mathematics and science courses were selected from Tehran through multi- stages clustering method. All subjects completed affective memory, task cost, math enthusiasm questionnaires and Data were analyzed using structural model and path analysis tests.

Results: According to results, negative memory had negative effects on ability-expectancy beliefs and positive memory had positive effects on $(\mathrm{P}>0 / 01)$. Negative memory had effects on math task value directly $(\mathrm{P}>0 / 01)$ as well as indirectly $(\mathrm{P}>0 / 01)$ with mediating role of ability-expectancy beliefs. Positive memory had effects on task value with mediation role of ability-expectancy beliefs directly and indirectly ( $\mathrm{P}>0 / 01)$. Ability -expectancy beliefs had effect on task value directly $(\mathrm{P}>0 / 05)$. Positive and negative memories had effects on math enthusiasm directly and indirectly $(\mathrm{P}>0 / 01)$. The direct relationship between Math self-schemas, Math task value and Math abilityexpectancy beliefs with math enthusiasm was not significant $(\mathrm{P}>0 / 05)$.

Conclusion: negative or positive memory had significant effect on math enthusiasm Also, Math selfschemas and Math Affective Because of ability-expectancy beliefs Affect of Math task value. Applied inspirations of findings were discussed.

* Corresponding Author: Esmaeil Saadipour, Professor, Department of Educational Psychology, Faculty of Psychology and Educational Sciences, Allameh Tabataba'i University, Tehran, Iran.

E-mail: ebiabangard@yahoo.com

Tel: (+98) 9121487053

2476-5740/ (C) 2021 The Authors. This is an open access article under the CC BY-NC-ND license

(https://creativecommons.org/licenses/by-nc/4.0/). 


\section{Extended Abstract}

\section{Introduction}

Interest in research on motivation and excitement in education has grown significantly. This growing interest in education coincides with a dramatic increase in attention to this field in many disciplines, including economics, neuroscience, anthropology, and the humanities (Lininberk, Packran, 2011). The concept of emotional, cognitive, and behavioral enthusiasm has been explored by researchers in recent years based on educational reforms for academic failure (Friedrichs, Bloomfred, Paris, 2004; Wang and Eccles, 2013). So far, studies with correlation, intervention, and modeling of structural equations have been conducted to identify the correlating factor or factors and predict the structure of academic motivation, but in research, the structure of academic motivation as Kelly is considered not in a particular field, so it is possible to examine passion on a particular subject and behavior, such as passion in mathematics (Wang et al., 2016). One of the mediating variables in this study that is related to academic self-schema on the one hand and mathematical passion on the other hand based on theoretical concepts and empirical evidence is mathematical ability-expectation beliefs. High ability-expectation beliefs have been positively associated with achievement behaviors, including academic motivation (Wigfield and Eccles, 2000; Wang, 2008; Mitswich et al., 2008; Cook and Artino, 2016). Another mediating variable of the model in this study is the value of the mathematical task. The value of homework is defined as the motivation to engage in different activities (Patricia, 2000).

Another mediating variable in this study, which based on theoretical concepts and empirical evidence is related to the beliefs of ability-expectation and task value on the one hand and to the style of attribution on the other hand, is the academic-mathematical schemas. Research shows that ability-expectation beliefs are influenced by motivational beliefs; one of our motivational beliefs is the academic self-schema (Wigfield and Eccles, 2002; Shank, Pintrich, 2002). According to the theoretical foundations, structural models and the results of the mentioned researches, the hypothetical model of the present research is drawn based on the expectation-value theory. To explain the effect of exogenous variables (mathematical self-plan and mathematical emotional memory) and mediating variables (abilityexpectation beliefs, mathematics and value of mathematical task) and to recognize the direct and indirect effects of these variables on the endogenous variable (mathematical passion), Provides a conceptual model in the form of the following input path diagram. As can be seen in the figure, this model has 4 models, some of which have first-order internal relations and some models have second-order internal relations. For example, in line with recent advances in educational psychology, it has been hypothesized that the task value construct has a second-order hierarchical structure. In the first order, the three observed indicators of success value, intrinsic value, external value and a latent indicator of task cost are formed, and the task cost in the lower order has four obvious indicators.

\section{Method}

A) Research design and participants: The present research method was correlational; The statistical population of this study was all 11th grade female students in Tehran $(\mathrm{N}=12986)$ who were studying mathematics and experimentation in ordinary public schools in the 98-97 academic year. The sample size was estimated according to the number of model parameters. Since there are 21 parameters, a sample of 560 people was selected in this study. Random cluster sampling method was used. In the first stage, the city of Tehran was divided into four regions in terms of geographical location: north (1), south (17), east (7), and center (6). General public girls' schools in District 1, 19 schools; District 6, 6 schools; District 7 had 9 schools and District 17 had 6 schools. Then four schools from each region and from each school an eleventh grade class in mathematics or experimental disciplines were randomly selected. 560 questionnaires were distributed and collected. Of these, 500 were completed and the information of the rest of the questionnaires was incomplete and were deleted. 


\section{Monthly Journal of Psychological Science}

B) Tools: Mathematical Enthusiasm: This questionnaire was developed by Fredericks et al. (2004) to measure students' academic achievement. It has 15 items and three subscales: Behavioral (1 to 4), Emotional (5 to 10) and Cognitive (11 to 15).. The answer of each item has a score of 1 to 5 , which includes from never to forever. Fredericks et al. (2004) reported the reliability coefficient of this questionnaire as 0.86. In the present study, Cronbach's alpha coefficient for mathematical enthusiasm was 0.81 .

Semnan Expectation-Value Questionnaire: Semnan Expectation-Value Questionnaire is used to measure the scales of math ability-expectation beliefs as well as the value of mathematical task. This questionnaire is based on the theory of expectation-value and the research of Eccles and Wigfield (1995, 2000); Eccles, Anil, Wigfield (2005); Welchdale (2003); Pintrich and Shank (2002); Watt, Eccles, Doric (2006) and Gao (2007) were made and translated into Persian by Hosseini, Talepasand and Bigdeli (2010). Students mark their answers to the questions on a 7-point Likert scale (1- Very Bad to 7- Very Good). The total score of this scale is obtained by calculating the mean of the questions (Simpkins and Davis-Kane, 2005).

Mathematical Emotional Memory Questionnaire: Emotional Memory was compiled into emotional memories of events following Shank et al. (2008) and Pilmer et al. (1996). Participants were asked to recall the most important event in their language class at school. Please think of something in your English class at school that has a special connection to you "and check that their experience consists of six positive emotions (happiness, hope, satisfaction, pleasure, pride and peace) and six negative emotions (fear, anger)., How bored, boredom, anxiety, embarrassment, and helplessness were in that situation (based on Pekran et al., 2002). This scale has 24 items. The questions in this tool are graded on a five-point scale from (strongly disagree $=1$ ) to strongly agree $=5$. Both positive emotional memory and negative emotional memory scales had good internal coherence. In a study by Georges and Candler (2012), Cronbach's alpha reported 0.91 for the negative emotional memory component and 0.83 for the positive emotional memory. The reliability of the
Vol. 20, No. 105, Autumn(December) 2021

questionnaire was estimated using Cronbach's alpha method and for each of the subscales of memory index, positive memory and negative memory, respectively $0.81,0.83$ and 0.78 and for the whole instrument 0.88 . Was obtained.

Self-Mathematical Schemas Questionnaire: The SelfStudy Schematic Questionnaire was developed by Garcia and Pintrich (1994). Academic schemas have four dimensions: emotion, efficiency, importance, and the future itself. Emotion dimension with 2 items Cronbach's alpha value 0.63 , efficiency dimension with 4 questions. Significance dimension with 4 questions and Cronbach's alpha value is 0.87 , selffuture dimension with 4 questions Cronbach's alpha value is 0.74 ( $\mathrm{NG}, 2005)$.

To analyze the data, central orientation indicators such as mean, standard deviation were used to describe the data and standard scores were used to identify outliers. Structural equation modeling was used to determine the suitability of the model and to estimate the coefficients of direct and indirect structural effects. Data were analyzed by AMOS software.

\section{Results}

Table 1 shows the information about the frequency of study of the sample members. Table 2 provides descriptive information about the mean and standard deviation along with the correlation coefficients between the observed study variables. Cronbach's alpha coefficients related to the reliability of the scores are also given on the main diameter of the matrix. As shown, the correlation coefficients between the dependent variables of mathematical enthusiasm and the self-variable components of mathematical schemas are positive and in the range between 0.25 to 0.40 , the components of variable memory are negative, negative and in the range of $0.14-0.35$, with positive memory in the range between 0.25 to 0.35 , with mathematical abilityexpectation beliefs in the range of 0.26 to 0.37 and with components of the value of mathematical task in the range of 0.25 to 0.38 and It is significant at the alpha level of $0.01(\mathrm{P}<0.01)$. The correlation between the components of mathematical enthusiasm and the components of task cost is negative and ranges from -0.09 to -0.29 and is significant at the alpha level of 


\section{Monthly Journal of Psychological Science}

0.05 ( $\mathrm{P}<0.05)$. The significance of the coefficients provides the necessary preconditions for the analysis of structural equations. Before analyzing the univariate outliers, the data were analyzed using a box diagram and the multivariate outsiders were analyzed using the Mahalanobis statistic and excluded from the data set. The skewness and elongation of the scores of the variables were calculated using SPSS software. The results showed that none of the values of skewness and elongation is more than $1 \%$. The normality of the data was checked using the Kalmogorov-Smirnov test. The results showed that the distribution of scores of the model variables is normal ( $\mathrm{P}<0.05)$. The hypothesis of error independence with Watson camera statistic was used to calculate the regression equations of the research model. The value obtained (Watson camera-statistic $=1.928$ ) indicates the establishment of this assumption. The alignment hypothesis between the variables was investigated using Pearson correlation between pairs of variables. Due to the fact that the
Vol. 20, No. 105, Autumn(December) 2021

correlation between two variables of 0.9 and above indicates linearity, this problem was not observed in the data of the present study.

In addition, tolerance statistics and variance inflation factor were calculated to investigate multiple alignment. The results showed that none of the tolerance statistics values were less than the allowable limit of 0.1 and none of the values of the variance inflation factor was greater than the allowable limit of 10. Therefore, based on the two indicators, there was no multiple alignment in the data. After examining the assumptions and ensuring their validity, structural equation analysis was used to evaluate the model under study.

Table 1: Frequency distribution of the sample of members of the sample group

\begin{tabular}{|c|c|c|}
\hline percentage & Frequency & field \\
\hline 54 & 270 & mathematics \\
\hline 46 & 230 & Experimental \\
\hline 100 & 500 & Total \\
\hline
\end{tabular}

Table 2. Structural equation model fit indices

\begin{tabular}{ccccccccc}
\hline AGFI & GFI & IFI & NFI & CFI & SRMR & RMSEA & $\chi \Upsilon / \mathrm{df}$ & Fit index \\
$>0 / 9$ & $>0 / 9$ & $>0 / 9$ & $>0 / 9$ & $>0 / 9$ & $<0 / 08$ & $<0 / 08$ & $\leq 5$ & Optimal amount \\
$0 / 885$ & $0 / 896$ & $0 / 904$ & $0 / 879$ & $0 / 903$ & $0 / 076$ & $0 / 083$ & $4 / 449$ & Initial model \\
$0 / 901$ & $0 / 907$ & $0 / 912$ & $0 / 887$ & $0 / 911$ & $0 / 062$ & $0 / 079$ & $4 / 130$ & The final model \\
\hline
\end{tabular}

Table 2 shows the fit indices of the final model. The root mean variance (RMSEA) appropriateness index (RMSEA) is 0.079 and the standard residual variance root (SRMR) is 0.62 , which indicates the optimal fit of the model. The IFI, CFI, GFI and NFI indices are also larger than the desired criterion (0.9). The obtained coefficients indicate the optimal fit of the model.

Table 3. Coefficients of measurement models in the structural equation model of the research

\begin{tabular}{ccccccc}
\hline $\mathrm{p}$ & $\mathrm{C} . \mathrm{R}$. & $\begin{array}{c}\text { Standard } \\
\text { coefficients }\end{array}$ & $\begin{array}{c}\text { Non-standard } \\
\text { coefficients }\end{array}$ & & & \\
\hline- & - & $0 / 84$ & 1 & affect & $\leftarrow$ & Math self-schemas \\
$0 / 01$ & $20 / 30$ & $0 / 78$ & $1 / 61$ & efficacy & $\leftarrow$ & Math self-schemas \\
$0 / 01$ & $24 / 86$ & $0 / 89$ & $1 / 91$ & importance & $\leftarrow$ & Math self-schemas \\
$0 / 01$ & $18 / 70$ & $0 / 73$ & $1 / 83$ & future self & $\leftarrow$ & Math self-schemas \\
- & - & $0 / 84$ & 1 & Fatigue & $\leftarrow$ & Negative memory \\
$0 / 01$ & $22 / 90$ & $0 / 85$ & $0 / 99$ & Disappointment & $\leftarrow$ & Negative memory \\
$0 / 01$ & $24 / 44$ & $0 / 89$ & $0 / 98$ & Anger & $\leftarrow$ & Negative memory \\
$0 / 01$ & $13 / 18$ & $0 / 72$ & $0 / 75$ & Anxiety & $\leftarrow$ & Negative memory \\
- & - & $0 / 67$ & 1 & joy & $\leftarrow$ & Positive memory \\
$0 / 01$ & $14 / 12$ & $0 / 84$ & $1 / 77$ & Pride & $\leftarrow$ & Positive memory \\
- & - & $0 / 92$ & 1 & Efficient expected & $\leftarrow$ & Ability/expectancy beliefs \\
$0 / 01$ & $23 / 19$ & $0 / 85$ & $0 / 61$ & Expected outcome & $\leftarrow$ & Ability/expectancy beliefs \\
- & - & $0 / 91$ & 1 & Intrinsic interest & $\leftarrow$ & Task value \\
$0 / 01$ & $19 / 12$ & $0 / 72$ & $0 / 55$ & Attainment value & $\leftarrow$ & Task value \\
$0 / 01$ & $19 / 54$ & $0 / 73$ & $0 / 43$ & Utility value & $\leftarrow$ & Task value \\
- & - & $0 / 77$ & 1 & task effort cost & $\leftarrow$ & Cost Task \\
$0 / 01$ & $17 / 18$ & $0 / 78$ & $0 / 90$ & loss of value alternatives & $\leftarrow$ & Cost Task
\end{tabular}




\begin{tabular}{ccccccc}
\hline $\mathrm{p}$ & C.R. & $\begin{array}{c}\text { Standard } \\
\text { coefficients }\end{array}$ & $\begin{array}{c}\text { Non-standard } \\
\text { coefficients }\end{array}$ & & & \\
\hline $0 / 01$ & $18 / 69$ & $0 / 86$ & $1 / 67$ & emotional cost & $\leftarrow$ & Cost Task \\
$0 / 01$ & $14 / 51$ & $0 / 66$ & $0 / 79$ & outside effort cost & $\leftarrow$ & Cost Task \\
- & - & $0 / 54$ & 1 & behavioral & $\leftarrow$ & Math Enthusiasm \\
$0 / 01$ & $8 / 87$ & $0 / 65$ & $2 / 67$ & emotional & $\leftarrow$ & Math Enthusiasm \\
$0 / 01$ & $8 / 57$ & $0 / 59$ & $1 / 71$ & cognitive & $\leftarrow$ & Math Enthusiasm \\
\hline
\end{tabular}

The results of the analysis of measurement models are presented in Table 3 . The significance of the regression weights for the six measurement models indicates that all the indices used for the latent variables are representativ.

Table 4: Direct, indirect effects of the lawyer in the final model

\begin{tabular}{cccccc}
\hline $\begin{array}{c}\text { Explanated } \\
\text { variance }\end{array}$ & $\begin{array}{c}\text { Total } \\
\text { effect }\end{array}$ & Indirect effect & $\begin{array}{c}\text { direct } \\
\text { impact }\end{array}$ & To variables & From the variable \\
\hline & $* * 0 / 51$ & - & $* * 0 / 51$ & Ability/expectancy & Math self-schemas \\
$0 / 61$ & $*-0 / 14$ & - & $* *-0 / 14$ & Negative memory \\
& $* * 0 / 21$ & - & $* * 0 / 21$ & Positive memory \\
& $* * 0 / 78$ & $* 0 / 07$ & $* *-0 / 72$ & Math self-schemas \\
$0 / 82$ & $*-0 / 16$ & $*-0 / 02$ & - & Task value & Negative memory \\
& $* 0 / 03$ & $* 0 / 03$ & $* 0 / 13$ & & Positive memory \\
& $* 0 / 13$ & - & $* *-0 / 23$ & Mbility/expectancy beliefs & Negative memory \\
$0 / 54$ & $*-0 / 23$ & - & $* * 0 / 58$ & Math Enthusiasm & Positive memory \\
\hline
\end{tabular}

\section{Conclusion}

The aim of this study was to develop and validate a structural model of mathematical passion based on self- mathematical schemas and mathematical emotional memory, mediated by math abilityexpectation beliefs and the value of mathematical homework. Based on this, a model was designed in which emotional mathematical memory and selfmathematical schemas were considered as exogenous variables and beliefs of ability-mathematical expectation and value of mathematical task were considered as mediating variables, and mathematical enthusiasm was considered as a consequence. The findings of this study not only confirmed the multidimensional nature of latent structures but also showed that in some cases these structures are hierarchical in nature.

The first path shows that mathematical self-plans have an indirect structural effect on the value of a mathematical task with the mediating role of mathematical expectation beliefs. The findings of the present study are consistent with studies that consider self-educational schemas as important as other selfschemas in terms of individual characteristics in an individual's academic identity. In other words, a person who has a positive self-schema in learning math is able to clearly show that learning math and math homework is important and valuable to him (NG, 2014).

The second path showed the effect of positive and negative emotional memory on the value of a mathematical task through mathematical abilityexpectation beliefs. Consistent with the present study, Pintrich and Shank (2002) showed that emotional memory can be activated by imagining homework and, through classical conditioning mechanisms or direct association, leads to positive or negative value for the individual. Assign. Students may place more value on this subject because of their positive experiences with a subject such as mathematics, and their interest in mathematics may increase, and even extend this interest to other activities (Pintrich and Shank, 2002).

The third path showed that negative memory and positive memory also have a direct structural effect on mathematical enthusiasm. Also, the direct effects of mathematical self-plans, the value of mathematical homework, and mathematical ability-expectation beliefs on mathematical enthusiasm are not significant. This finding is consistent with the research of Georges and Candler (2012). 


\section{Psychological Science}

Ethical Considerations

Compliance with ethical guidelines: This article is taken from the doctoral dissertation of the first author, majoring in educational psychology at Allameh Tabatabai University. The date of approval of the proposal. Also, licenses related to research in the statistical community have been issued by education.

Funding: This study was conducted as a PhD thesis with no financial support.
Vol. 20, No. 105, Autumn(December) 2021

Authors' contribution: The first author is the main researcher of this research. The second and third authors are the supervisors and the fourth and fifth authors are the advisory professors of the dissertation.

Conflict of interest: the authors declare no conflict of interest for this study.

Acknowledgments: We would like to thank the supervisors and consultants who helped in this research

Acknowledgments: We would like to thank the supervisors and consultants who helped in this research. 


\section{رابطه ساختارى خودطرحوارههاى رياضى و حافظه عاطفى رياضى با اشتياق رياضى: نقش ميانجى ارزش تكليف و باوروهاى توانايى انتظار}

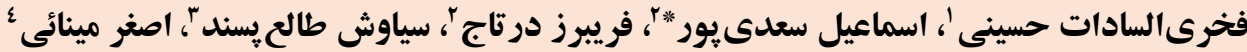 \\ ا. دانشجوى دكترى روانشناسى تربيتى، دانشكده روانشناسى و علوم تربيتى، دانشكاه علامه طباطبائى، تهر ان، ايران. \\ r. استاد، گروه روانشناسى تربيتى، دانشكده روانشناسى و علوم تربيتى، دانشكاه علامه طباطبائى، تهران، ايرانيان.

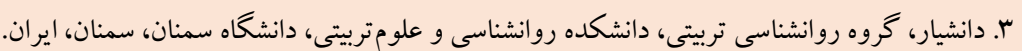 \\ F. دانشيار، گروه سنجش و اندازهيرى، دانشكده روانشناسى و علوم ترييتى، دانشكاه علامه طباطبائى، تهران، ايران.}

\section{جكيده}

زمينه: مطالعات متعددى به بررسى اشتياق تحصيلى برداختهاند. اما بروهش بيرامون تدوين مدل ساختارى براى بيشبينى اشتياق رياضى بر اساس خودطرحو اره رياضى و حافظه عاطفى رياضى با ميانجى گرى ارزش تكليف و باورهاى تو انايى - انتظار مغفول مانده است. هدف: هدف از يزوهش حاضر بررسى رابطه ساختارى حافظه عاطفى و خو دطرحواره رياضى با اشتياقرياضى با نقش ميانجى باورهاى توانيى - انتظار و ارزش تكليف بود. روش: اين يُزوهش از نوع يُزوهش همبستخى با استفاده از مدليابى معادلات ساختارى بود كه ...ه نفر از دانش آموزان بِايههاى يازدهم

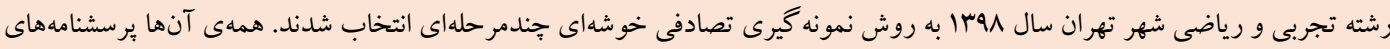

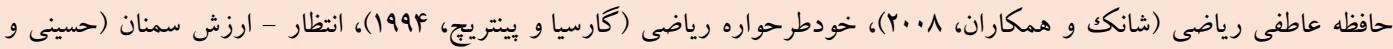

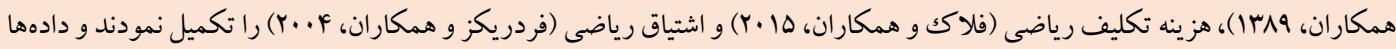
با استفاده از آزمونهاى مدل ساختارى و تحليل مسير تحليل شد. يافته ها: بر اساس نتايج بدست آمده، حافظه منفى به صورت مستقيم بر باورهاى تو انايى - انتظار رياضى، تأثير منفى و حافظه مثبت به صورت

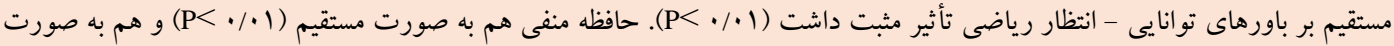

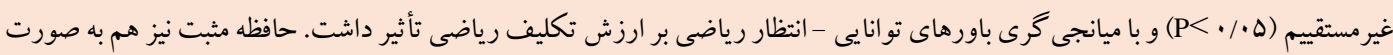

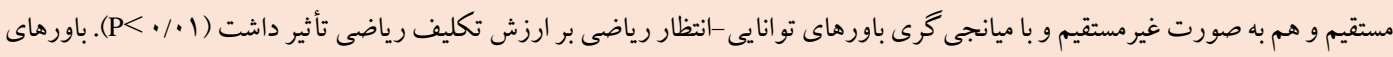
تو انايى - انتظار رياضى نيز به صورت مستقيم بر ارزش تكليف رياضى تأثير داشت (ه •/P<). حافظه منفى و هم حافظه مثبت هم به صورت

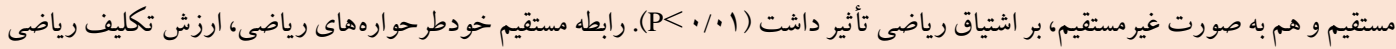
و باورهاى توانايى - انتظار رياضى با اشتياق رياضى معنىدار نبود (ه • • (p). نتيجه كيرى: حافظه عاطفى مثبت و منفى بر اشتياقرياضى مؤثر است. همجنين خودطرحواره رياضى و حافظه عاطفى رياضى به واسطه

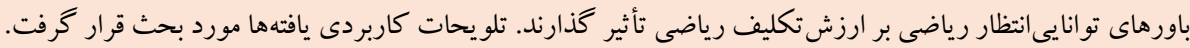

مشخصات مقاله

كليدوازه内ها:

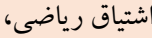

خودرطر حوارههاى رياضى،

حافظه عاطفى رياضى، باورهاى توانيى - انتظار رياضى، ارزش تكليف

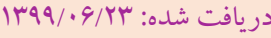

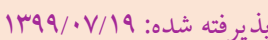

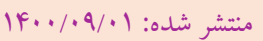

* نويسنده مسئول: اسماعيل سعدى يور، استاد، گروه روانشناسى تربيتى، دانشكده روانشناسى و علومتربيتى، دانشگاه علامه طباطبائى، تهران، ايران. رايانامه: ebiabangard@yahoo.com

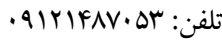


اين كه صاحبنظران معتقدند تفاوت در اشتياق تحصيلى، صرفا تحت تأثير مقلمه

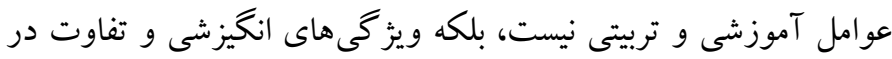

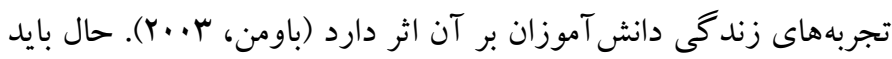

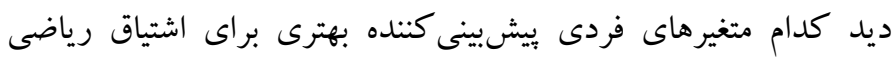
هستند، كه به دركك بهتر و منسجم تر اين سازه و مؤلفهاى آن كمكك

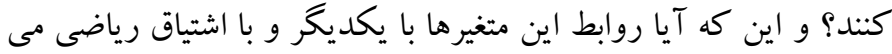

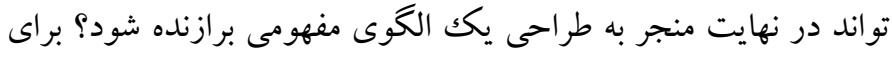

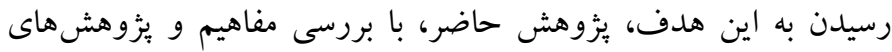

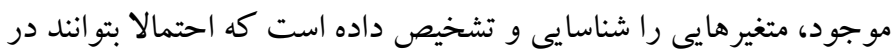
تبيين اين سازمى سرنوشت ساز نقش مؤثرى داشته باشند. در ادامه به معرفى مفاهيم نظرى مرتبط و متغيرهاى مورد نظر برداخته مى شود.

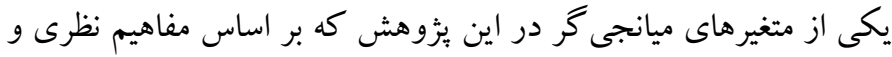

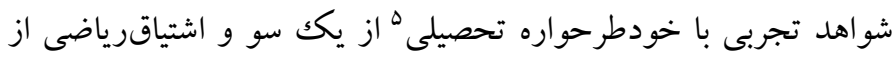

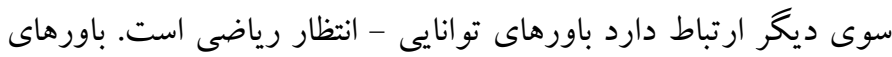
توانيى - انتظار بالا با رفتارهاى بيشرفت از جمله اشتياقتحصيلى رابطه

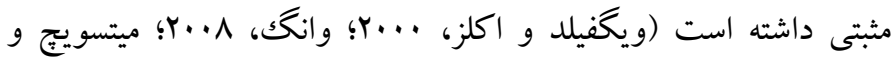

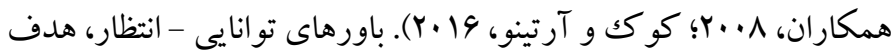

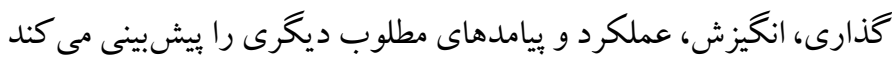

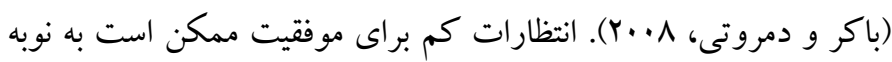
خود منجر به اجتناب از كار و كوشش كمتر و بايدارى كمتر شود (قدم

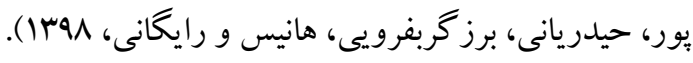

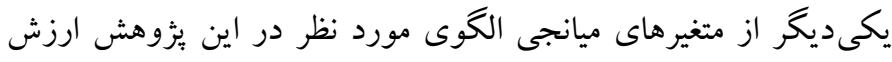

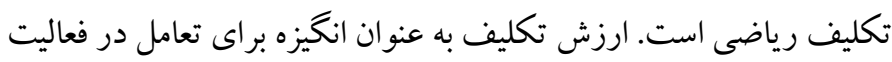

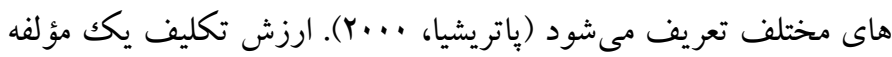

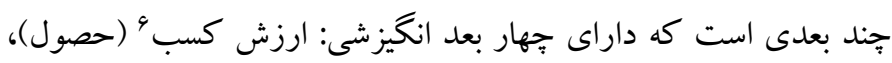

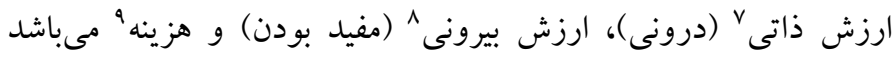

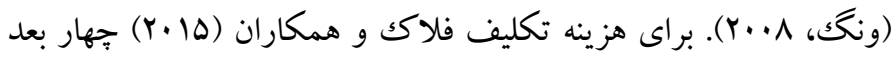
هزينه هيجانى، هزينه تلاش درونى، هزينه از دست دادن فرصتهاى رقيب ريب

6. Attainment value

7. Intrinsic interest

${ }^{8}$. Utility value

${ }^{9}$. Cost
علاقه به يثوهش در مورد انگيزش و هيجان در آموزش و يرورش رشد قابل ملاحظهاى يافته است. اين علاقه روزافزون در آموزش، همزمان با افز ايش جشمخير تو جه به اين حيطه در بسيارى از رشتههاى علمى از جمله اقتصاد، علوم اعصاب، انسان شناسى و علوم انسانى مىباشد (لينينبر ك؛،

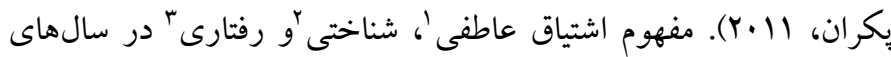
اخير توسط يزوهشخران بر مبناى اصلاحات در حوزه حوزه تعليم و تربيت براى افت و شكست تحصيلى، مطرح و مدنظر قرارگر فته است (فريدريكز،

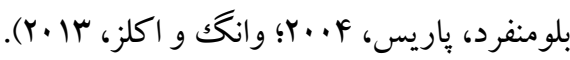

با وجود حجم فز آينده مطالعات مرتبط با اشتياق در سالهاى اخير مفهوم اشتياق تحصيلى "هنوز مبهم باقى مانده است (زانگك، سا +r؛ وانگك و اكلز،

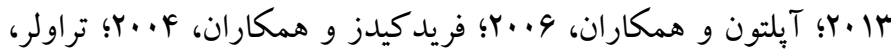

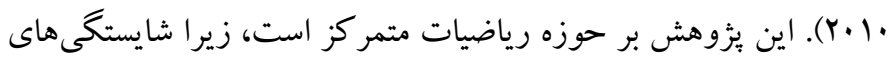
رياضى بيش شرطهاى مهم براى قابليتهاى عمومىتر، مانند حلمسئله سيستماتيك و مهارتهاى تحليلى، كه بيش نيازهاى مهم مشاركت

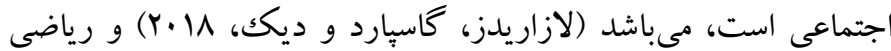
نقش مهمى در زندگى روزمره دارد (فلاحان، محمودنيا، قائدى و ضرغامى

$(1499)$

تاكنون يثزوهشهايى با روش همبستخى، مداخلهاى، و الكويابى معادلات ساختارى، براى شناسايى عامل يا عو امل همبسته و بيشبينى كنندهى سازه اشتياق تحصيلى انجام كرفته است، اما بيشتر اين يزوهشها به شكل يكك بعدى بررسى كردهاند يا يثوهش هايى هم كه تا كنون، به صورت جندجانبه (الكوى ساختارى) به بررسى عوامل مؤثر بر اشتياقتحصيلى يرداختهاند، ابعاد شناختى و انخيزشى را مورد بررسى قرار ندادند (اسجمتو و درس،

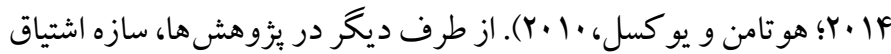
تحصيلى به صورت كلى در نظر گرفته شده است نه در يك حوزه خاص، ازاينرو مى توان اشتياق را بر روى يكك موضوع و رفتار خاص مثلا اشتياق در حوزه رياضيات بررسى كرد (وانگك و همكاران، 19 با.ب). افزون بر آن

${ }^{1}$. emotional enthusiasm

2 . cognitive

3 . behavioral

4. Academic enthusiasm

5 . Academic self-schemas 
فعاليتهاى ياد گيرى كذشته، حافظه عاطفى ناميده مىشوند. مؤلفهاى انكيزشى مثل حافظه عاطفى بر عملكرد و اشتياق تحصيلى اثر كذارند

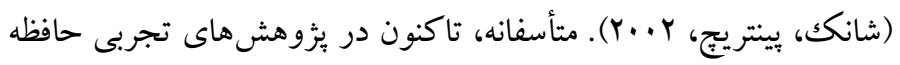
عاطفى به عنوان بيش در آمد ارزش تكليف و باورهاى - توانايى انتظار ناديده

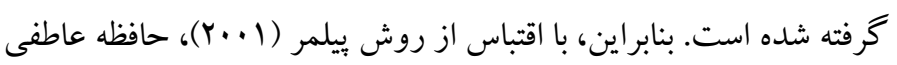
را اتفاقات مهم از دوران مدرسه تعريف مى كنيم. مسأله اساسى در بززوهش حاضر بررسى نقش ميانجى گر متغيرهاى باورهاى

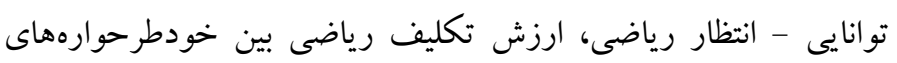

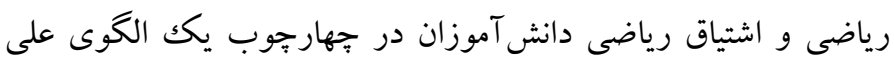

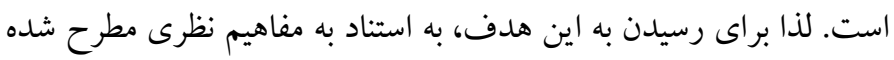

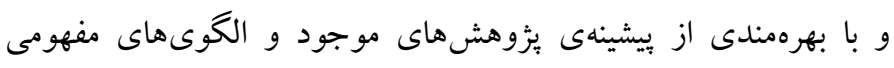

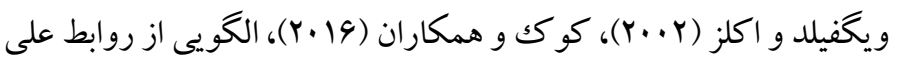
ميان متغير ها مورد آزمون و بررسى قرار خو اهد گرفت. آنجه باعث متمايز

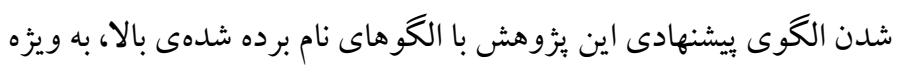

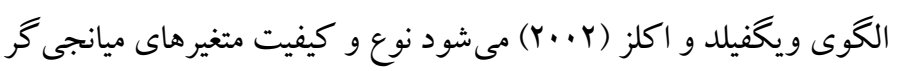
است كه قابل آموزش و ارتقا هستند.

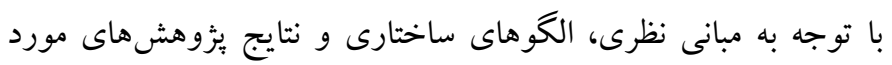

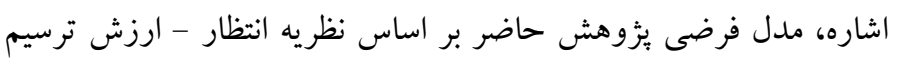

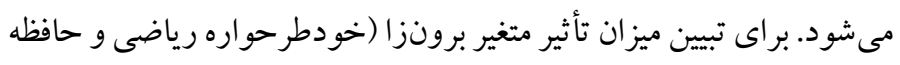

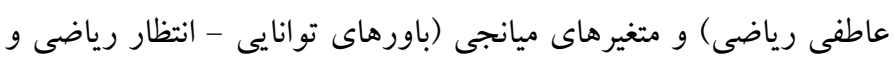

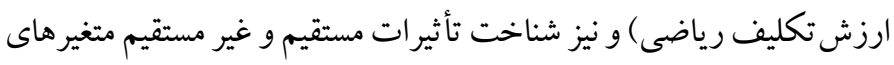
مزبور بر متغير درونزا (اشتياق رياضى)، الكوى مفهومى در قالب نمودار مسير ورودى زير ارائه مىدهد. همان طور كه در شكل مشاهده مى شىود اين

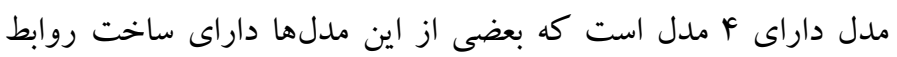
درونى مرتبه يكم و بعضى مدلها داراى ساخت روابط درونى مرتبه دوم

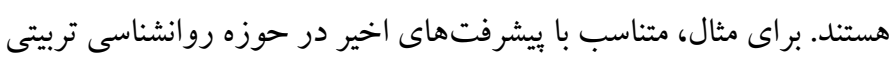

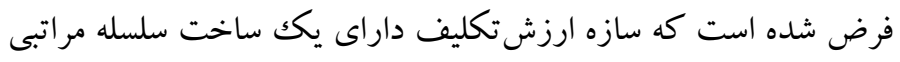

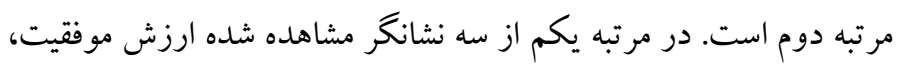
ارزش درونى، ارزش بيرونى و يكك نشانكر نهفته هزينه تكليف تشكيل شده ديه دئه

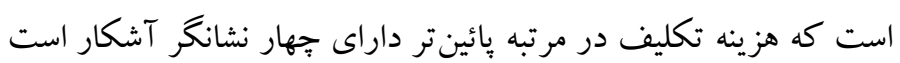

و هزينه تلاش بيرونى را شناسايى كردهاند. بثزوهشگر ان نشان دادهاند كه به

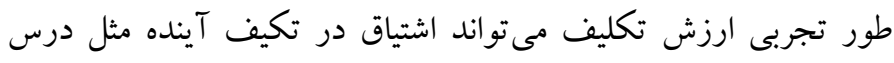

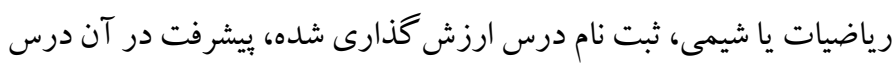

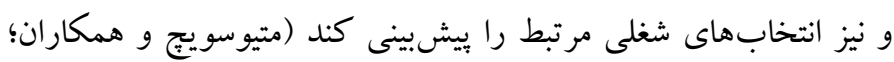

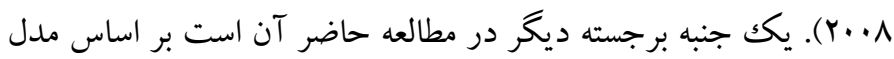

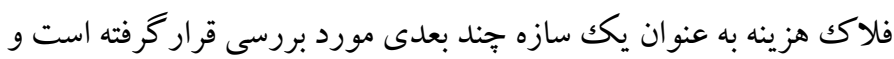

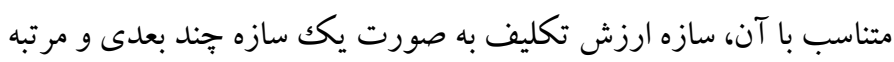
دوم مورد ارزيابى شده است.

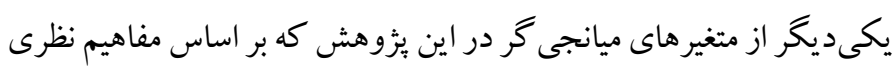

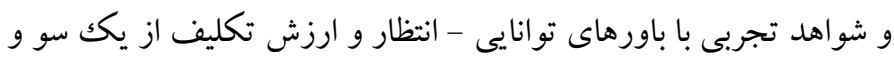

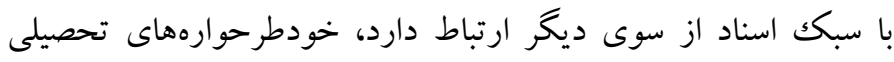
رياضى است. يُزوهشها نشان مىدهند باورهاى توانايى - انتظار متأثر از

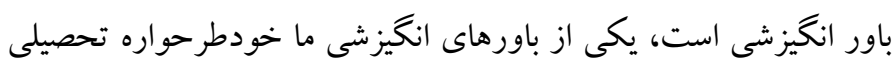

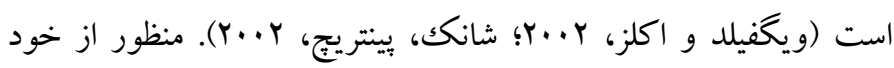
طرحواره تحصيلى برداشت كلى است كه فرد دربارهٔ توانايى خود در حوزه يكك تكليف خاص دارد (براى مثال، توانايى تحصيلى، قابليت ورزشى،

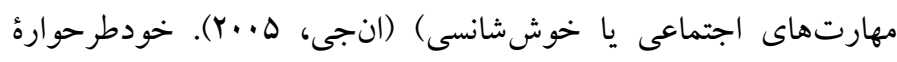

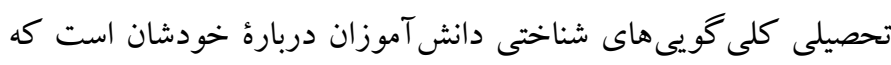

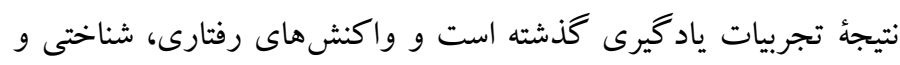
عاطفى دانش آموزان نسبت به يادكيرى را هدايت مى كند)، (ماركوس،

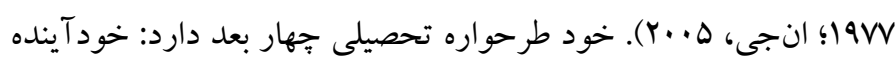

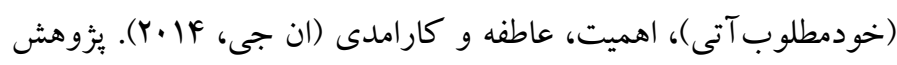

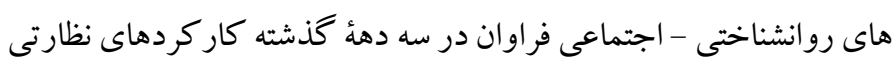

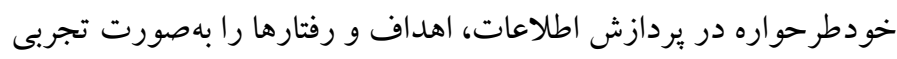

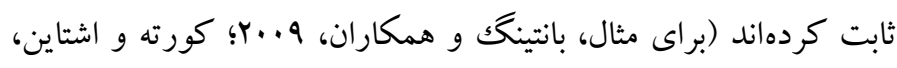

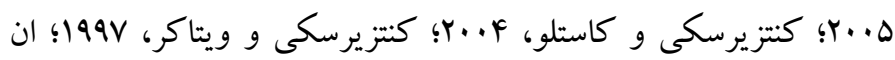

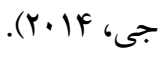
با مطالعهاى كه از شو اهد تجربى و ادبيات موضوع مورد بررسى انجام شد ند

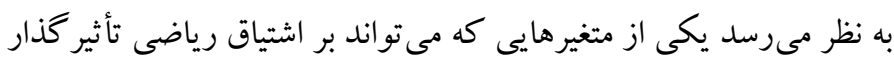

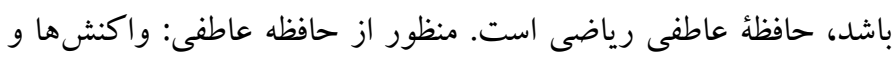
احساسات مربوط به تجربيات قبلى است (نو الز، هولتون و اسو انسن، هـ م. (Y).

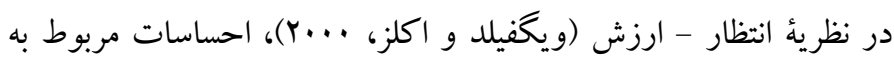




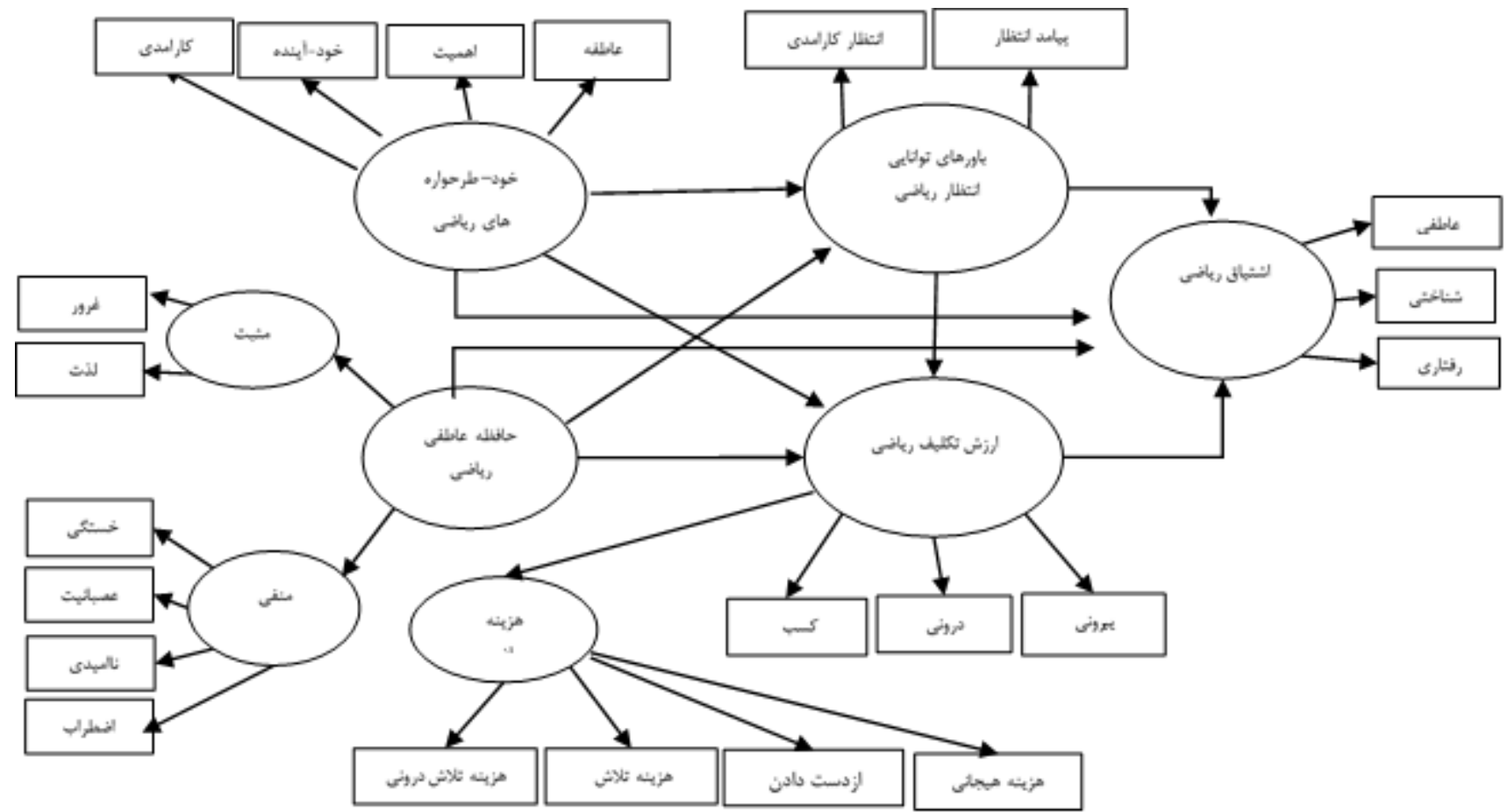

شكل ا. روابط ساختارى حافظه عاطفى رياضى با اشتياق رياضى با نقش ميانجى باورهاى توانايى انتظار و ارزش تكليف

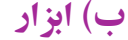
اشتياق رياضى': اين برسشنامه توسط فردريكز و همكاران (Y...F) براى

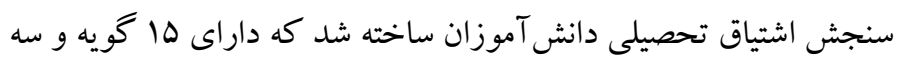

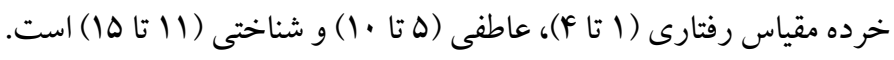

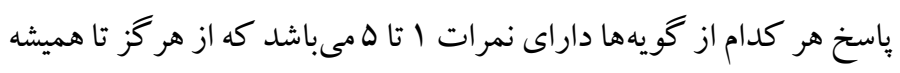
را شامل مىشود، حداقل و حداكثر نمره و نقطه برش در كل يرسشنامه

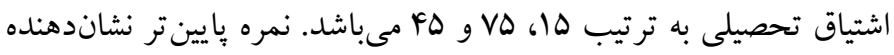
اشتياق تحصيلى كم و نمره بالاتر نشان دهنده اشتياق تحصيلى زياد مىباشد.

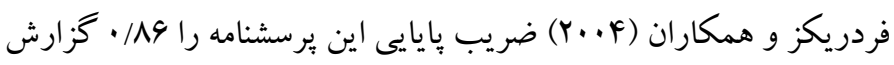

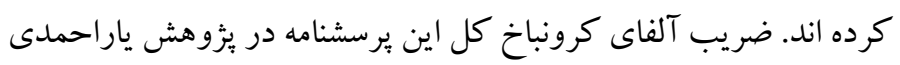

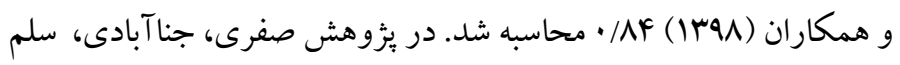

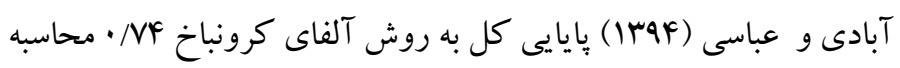

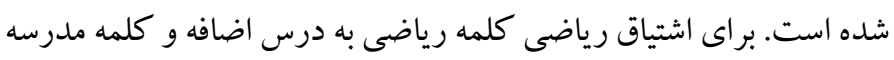
حذف شد. در يزوهش حاضر نيز ضريب آلفاى كرونباخ براى اشتياق رياضى ای// ب بهدست آمد.

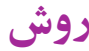
الف) طرح ئوهش و شر كت كنند كان: روش يزوهش حاضر از نوع

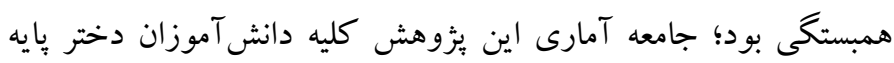

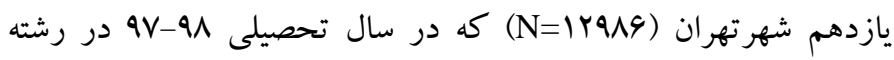
رياضى و تجربى كه در مدارس عادى دولتى مشغول به تحصيل بودند.

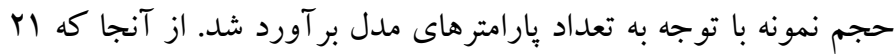

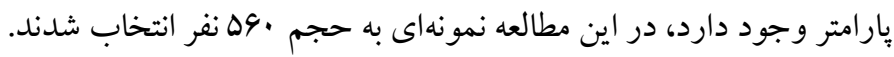

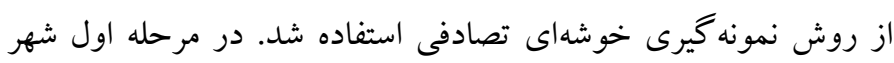
تهر ان از لحاظ موقعيت جغرافيايى به جهار منطقه شمال (1)، جنوب (IV) (IV)، شرق (V)، و مركز (9) تقسيم شد. به طور كلى مدارس عادى دولتى دخترانه در منطقه 1، 19 مدرسه؛ منطقه 9، 9 مدرسه؛ منطقه V، 9 مدرسه و منطقه

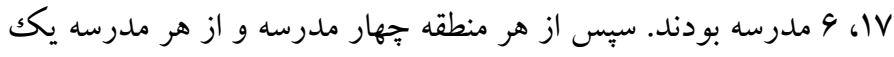

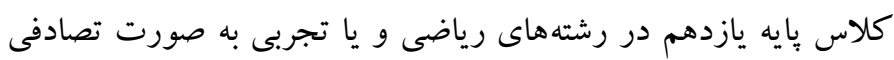

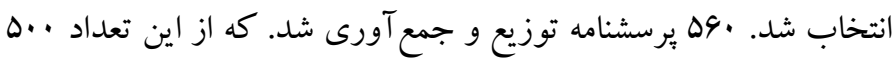
عدد كامل بر شده و اطلاعات بقيه يرسشنامه ها ناقص بود كه حذف شدند.

1. Math Enthusiasm 
براى زندگى روزانه شما در خارج از مدرسه مفيد است؟ ". اين سؤ الها بر

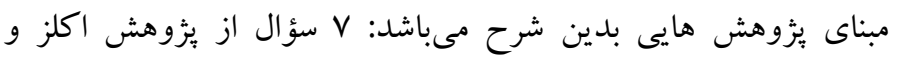

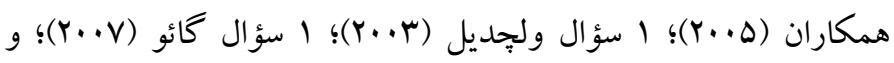

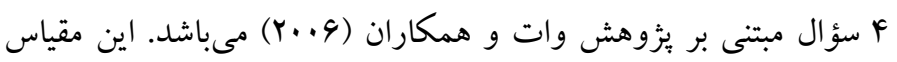
اعتبار عالى و ويزگ گیىاى روانسنجى قوى دارد (آندرمن، اكلز، يوون،

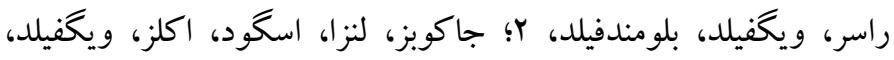

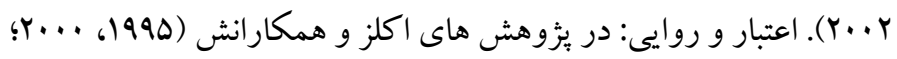

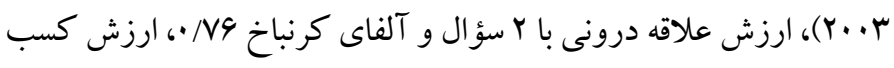

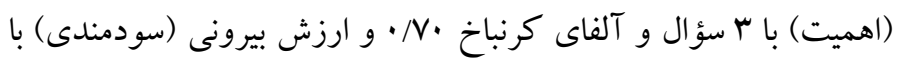

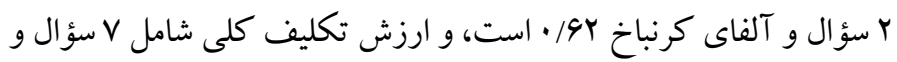

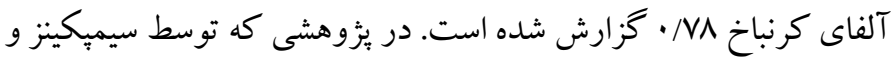

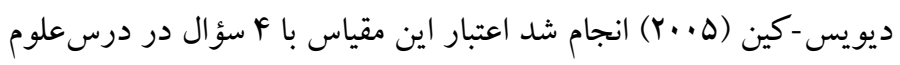

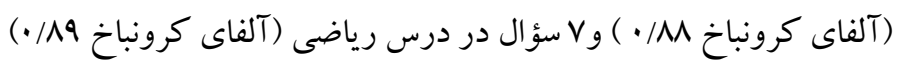

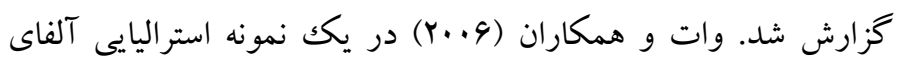

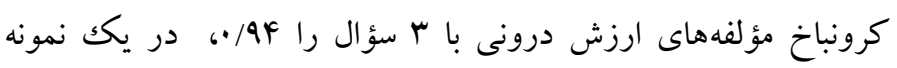

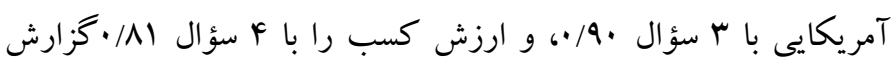

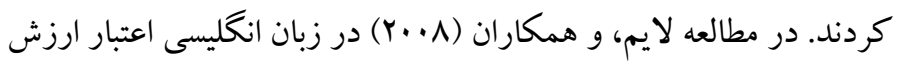

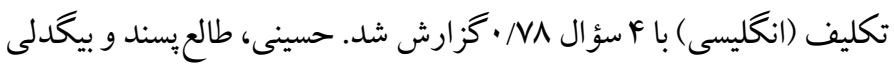

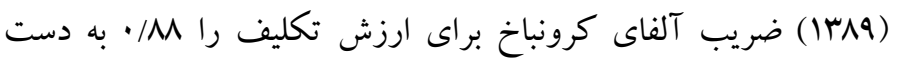

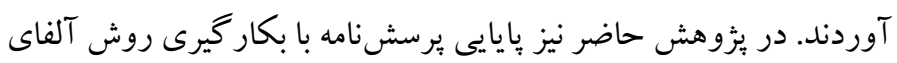

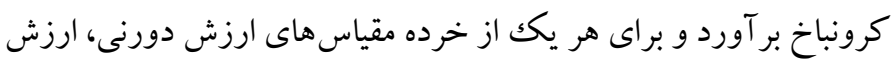

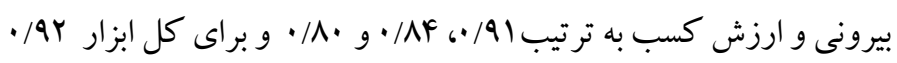
به دست آمد.

برسشنامه هزينه تكليف رياضى ": در بثزوهش حاضر براى اندازه كيرى مؤلفه

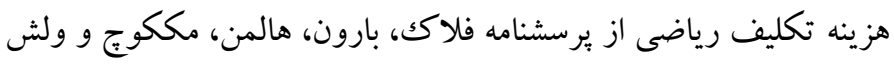

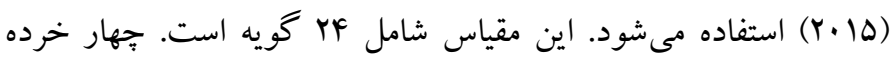
مقياس هزينه تلاش درونى (4 گويه)، هزينه تلاش بيرونى (ه گويه)، هزينه

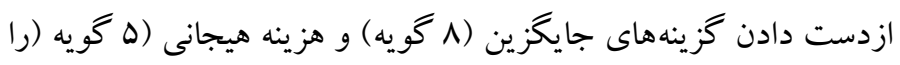

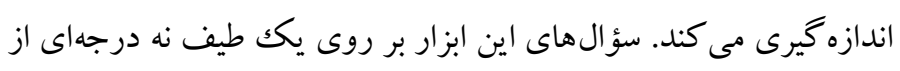

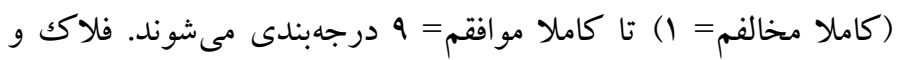

3. Math Task value

4. Task Cost Scale (TCS)
يرسشنامه انظار - ارزش سمنان ': براى اندازهگيرى مقياسهاى باورهاى

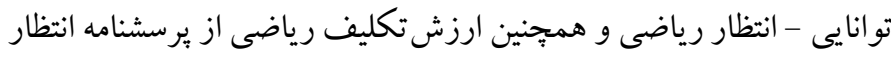

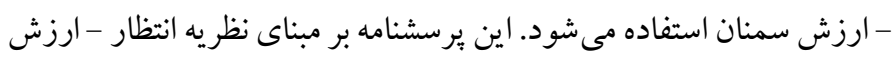

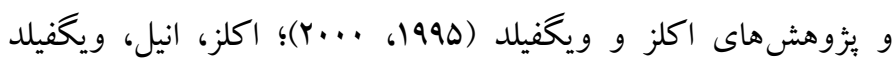

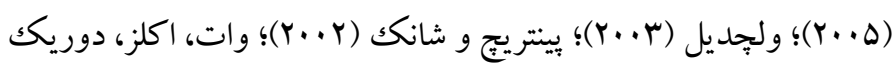

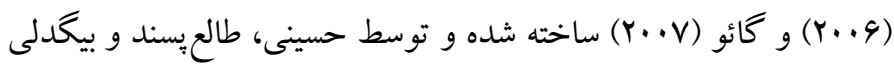

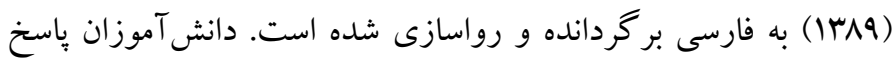

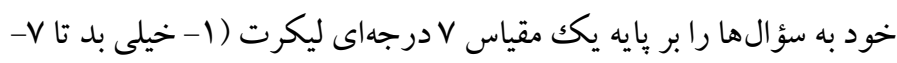

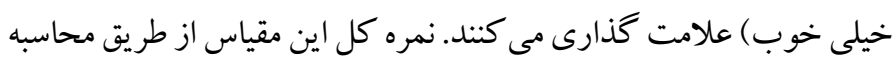

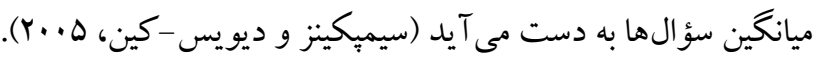

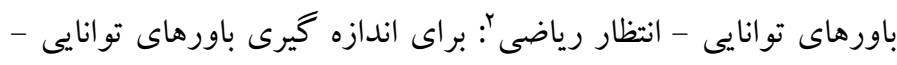

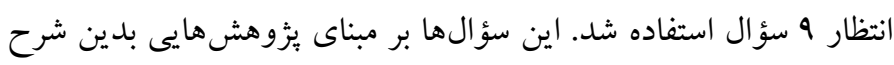

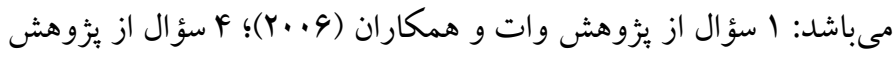

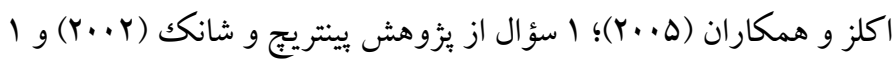

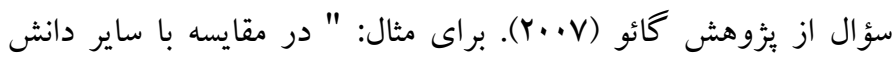

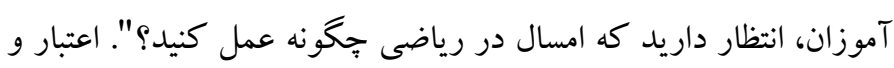

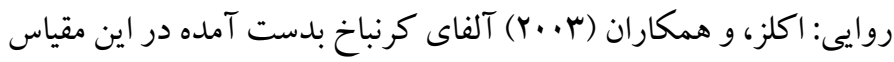

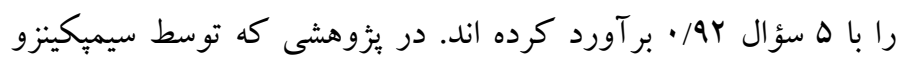

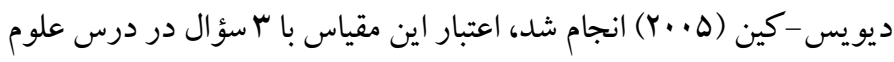

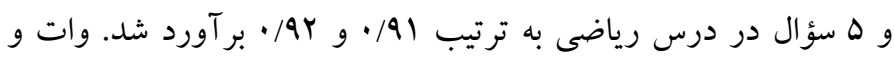

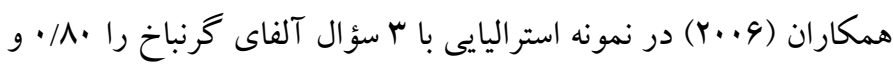

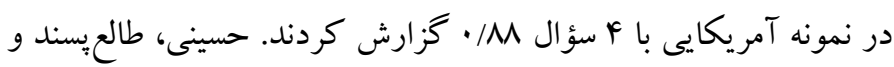

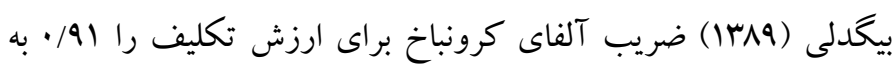

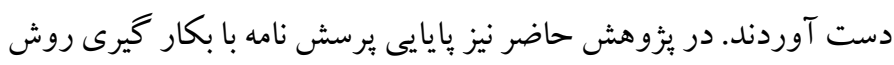

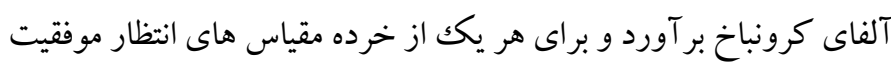

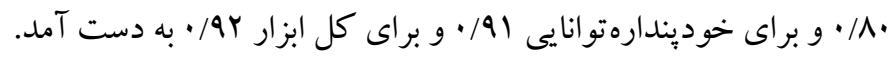

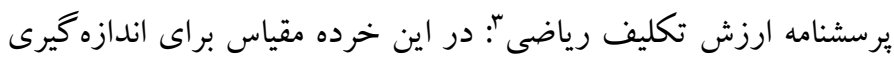

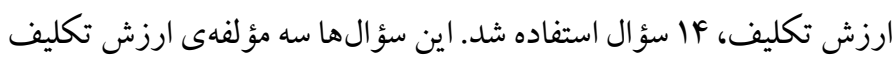
يعنى، ارزش كسب، ارزش علاقه درونى، ارزش علاقه بيرونى را اندازه

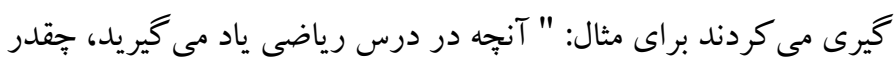

1. Semnan Expectancy-Value Questionnaire

${ }^{2}$. Math Ability/expectancy beliefs 
مخالفم= (1) تا كاملا مو افقم = ه درجهبندى مىشوند. هر دو مقياس حافظه عاطفى مثبت و حافظه عاطفى منفى از انسجام درونى مطلوبى برخوردار

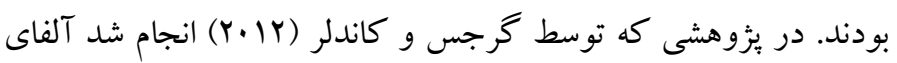

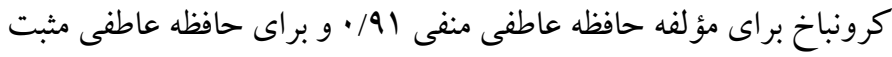

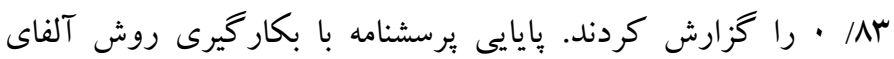

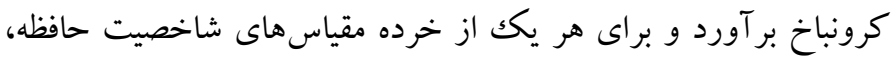

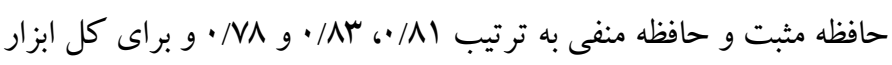

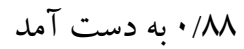

يرسشنامه خودطرحوارههاى رياضى": يرسشنامه خودطرحواره تحصيلى

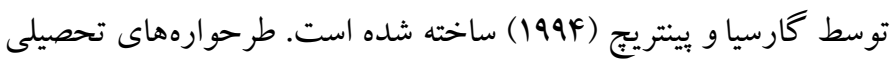

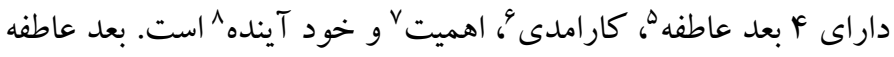

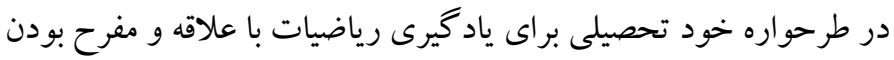

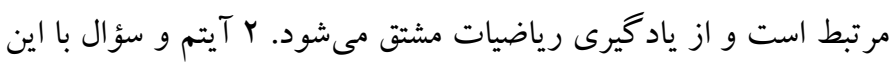

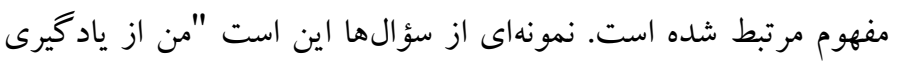

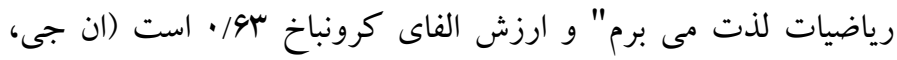

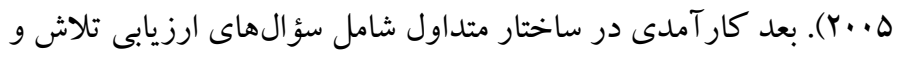
تو انايى صرف شده دانش آموزان در عملكرد رياضيات مىشود. F سؤال

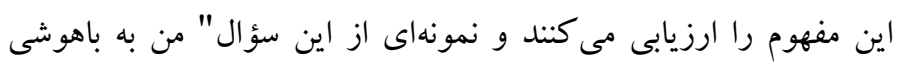

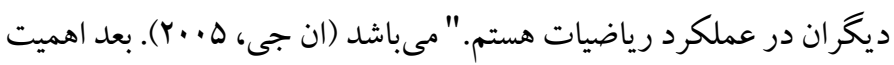

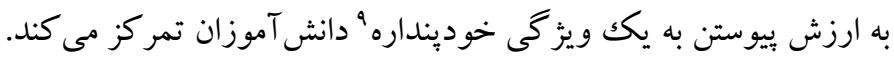

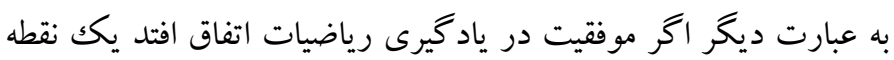

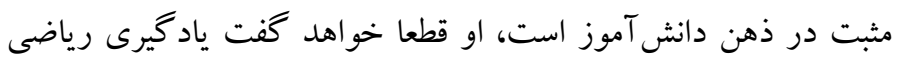
بخش ارزشمندى در وجود من است. اين مفهوم، هسته مفهوم خود ماركوس را تصرف كرده و F سؤال اين مفهوم را اندازه گيرى مى كنئد.

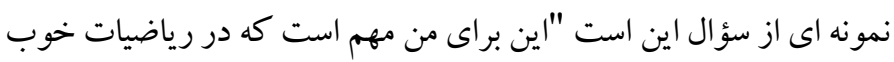

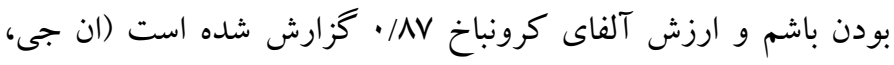

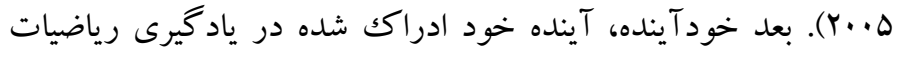

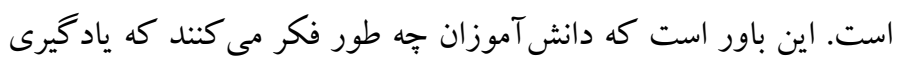

5. affect

${ }^{6}$. efficacy

7. importance

${ }^{8}$. future self

${ }^{9}$. self-conception

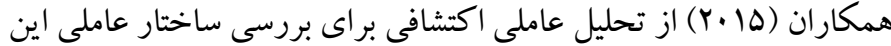
مقياس استفاده كردند. فلاكك و همكاران (10 +Y) ميز ان اعتبار را با استفاده

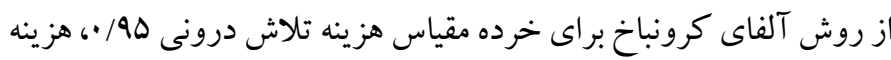

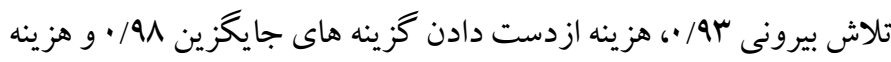

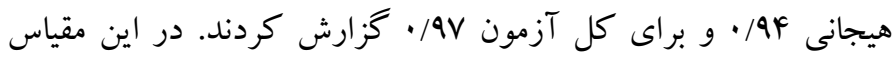

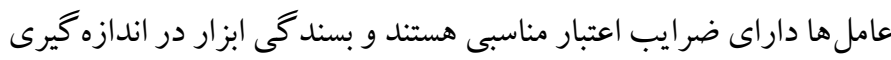

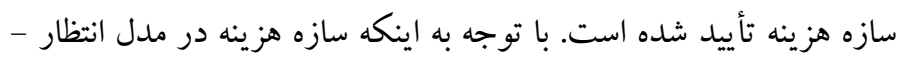

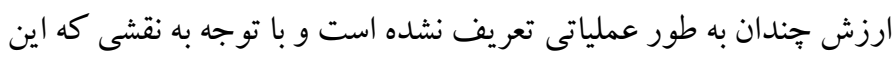

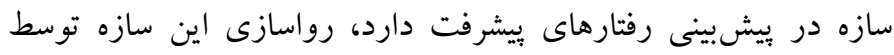

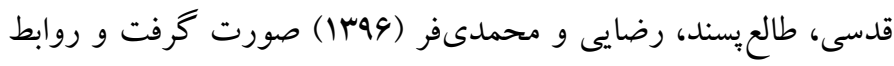
درونى هزينه تكليف در يكك مدل جهار عاملى آزمون شد. يافتها نشان داد

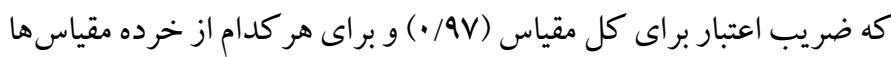

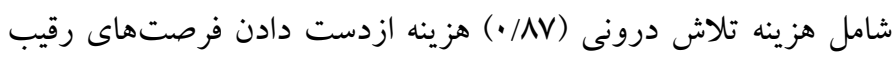

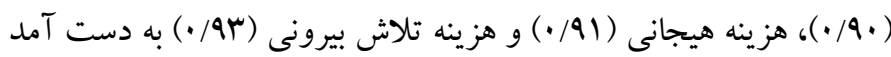

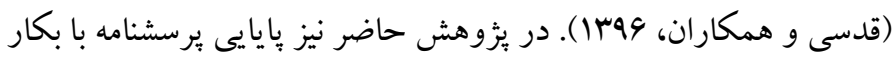

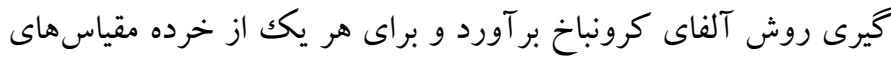

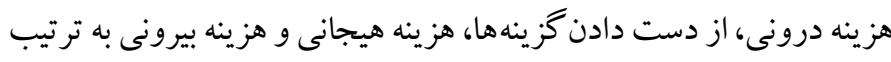

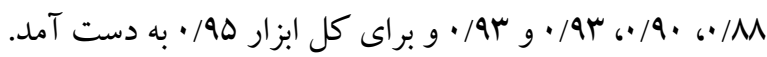

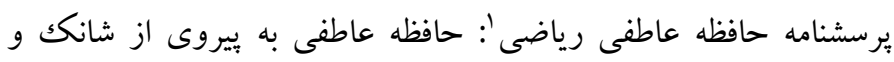

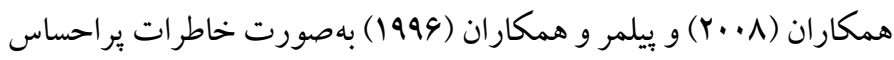
از اتفاقات مهفومسازى شدند از شركت كنندكان خواسته شد مهمترين اتفاق كلاس زبان خود در مدرسه رابه خاطر آورند "لطفاً به اتفاقى از

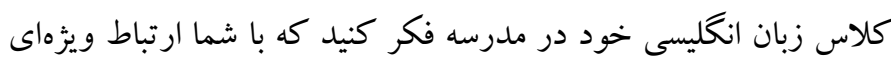
دارد" و بررسى كنيد كه تجربة آنها از شش احساس مثبت (شادى، اميد،

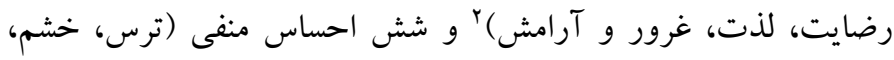

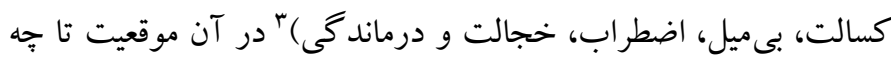

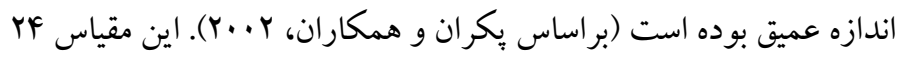

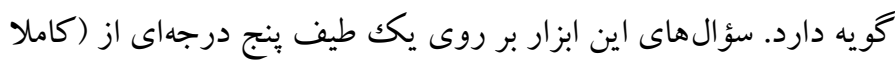

${ }^{1}$. Math Affective Memories

2. AMPOS: joy, hope, satisfaction, fun, pride, \& relief

3. AMNEG: fear, anger, boredom, reluctance, anxiety, shame, \& hopelessness

${ }^{4}$. Math self-schemas 
اصلى ماتريس آورده شده است. همانكونه كه نشان داده شده است ضرايب همبستكى بين مؤلفهاى متغير وابسته اشتياق رياضى با مؤلفه هاى

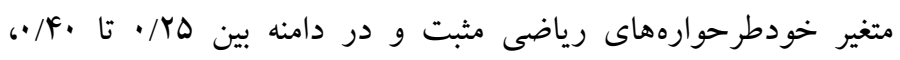
مؤلفه هاى متغير حافظه منفى، منفى و در دامنه FF/.-- تا هץ/·--، با حافظه مثبت در دامنه بين هץ/· تا هس/•، با باورهاى توانايى - انتظار رياضى در دامنه צY/ • تا VV/ • و با مؤلفههاى ارزش تكليف رياضى در دامنه هץ/• تا ^ץ/· بوده و در سطح آلفاى I • • معنى دار است (1 • • > P). همبستكى بين مؤلفه هاى اشتياق رياضى با مؤلفههاى هزينه تكليف منفى و در دامنه

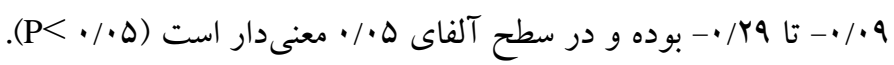
معنى دارى ضر ايب بيش شرط لازم براى تحليل معادلات ساختارى را فراهم مى آورد. يِيش از انجام تحليل دادههاى يرت تكك متغيرى با استفاده از نمودار جعبهاى و دادههاى برت جندمتغيرى با استفاده از آماره ماهالانوبيس بررسى و از مجموعه دادهها كنار كذاشته شدند. كجى و كشيدكى توزيع نمر ات متغير ها با استفاده از نرمافزار SPSS محاسبه شد. نتايج نشان داد هيج كدام از مقادير كجى و كشيدكى بيشتر از دامنه إنى نمىباشد. نرمال بودن دادهها با استفاده از آزمون كالموكروف_اسميرنوف بررسى شد. نتايج نشان داد توزيع نمرات متغيرهاى مدل نرمال است (ه> • (P>). فرض استقلال خطاها با آماره دوربين واتسون براى محاسبهى معادلات ركرسيونى مدل يزٔوهش بررسى شد كه مقدار به دست آمده

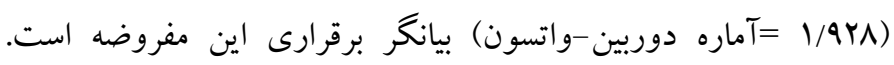
مفروضهى هم خطى بين متغير ها با استفاده از همبستگى بيرسون بين زوج متغير ها بررسى شد. با تو جه به اينكه همبستكى دو متغيرى 9/ • و بالاتر نشان دهندهى همخطى است، اين مشكل در دادهاى يثزوهش حاضر مشاهده نشد.

علاوه بر آن آماره تحمل و عامل تورم واريانس به منظور بررسى هم خطى جند گانه محاسبه شد. نتايج نشان داد هيجِكدام از مقادير آماره تحمل كو جִكتر از حد مجاز / / • و هيجّدام از مقادير عامل تورم واريانس بزرگتر از حد مجاز · ا نمىباشند. بنابراين بر اساس دو شاخص ذكر شده وجود همخطى جند گانه در دادهها مشاهده نشد. يس از بررسى مفروضهها و حصول اطمينان از برقرارى آنها، به منظور ارزيابى مدل مورد بررسى از تحليل معادلات ساختارى استفاده شد. نتايج در شكل r ارائه شده است.
رياضيات مهم است، آن يادگيرى لذتبخش است و باور كار آمد قوى در انجام آن دارند، به طور معمول انتظار دارد كه آينده خود را در رياضيات

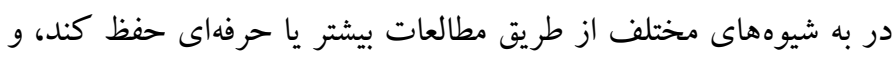

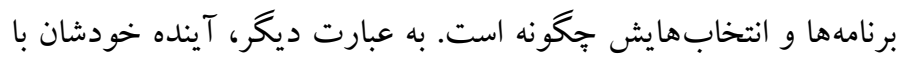

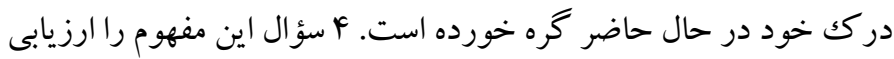

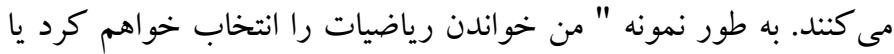
ساير موضوعات مرتبط را مطالعه خواهم كرد. ارزش آلفاى كرونباخ

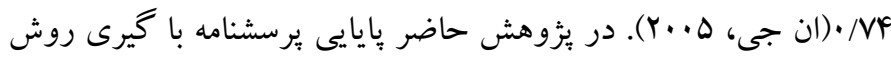

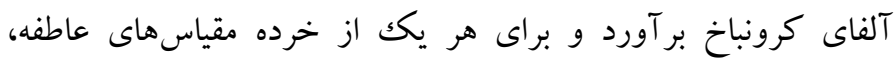

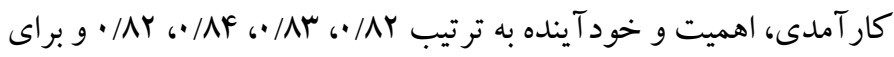

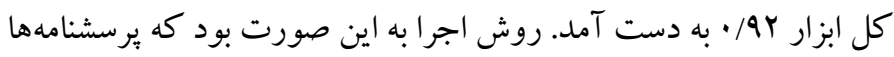

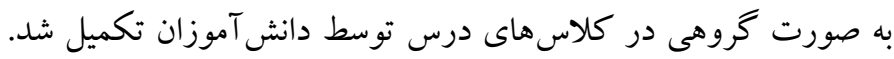

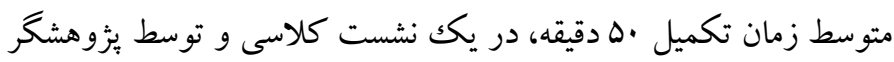

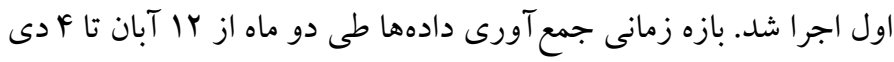

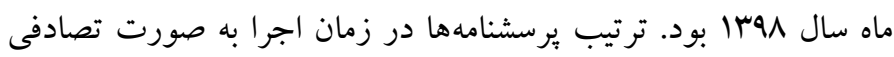

$$
\text { متغير بود تا اثر ترتيب و خستخى خنثى شود. }
$$

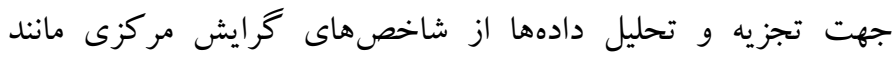

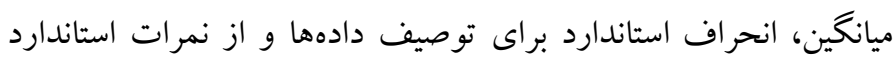
براى شناسايى مقادير يرت استفاده شد. از مدل يابى معادلات ساختارى

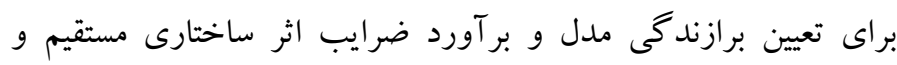

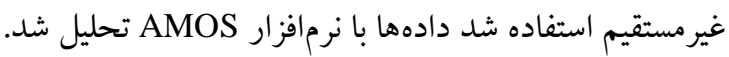

يافتهها

\begin{tabular}{|c|c|c|}
\hline درصد & فراوانى & رشته \\
\hline$\Delta F$ & $r V$. & رياضى \\
\hline kq & $r r$. & تجربى \\
\hline $1 .$. & $\Delta .$. & كل \\
\hline
\end{tabular}

در جدول ا اطلاعات مربوط به فراوانى رشته تحصيلى اعضاى نمونه نشان

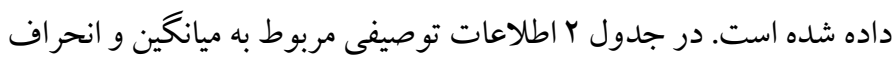

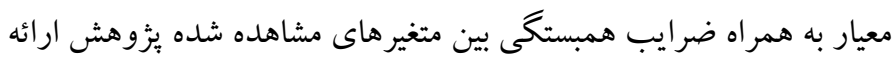

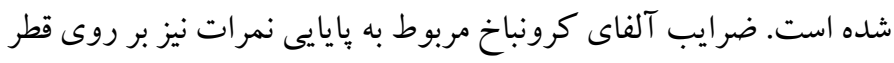

1. Structural Equation Modeling 


\begin{tabular}{|c|c|c|c|c|c|c|c|c|c|c|c|c|c|c|c|c|c|c|c|c|c|c|}
\hline rY & rI & $r$. & 19 & 11 & IV & 19 & 10 & if & ir & ir & 11 & 1. & 9 & $\wedge$ & $\checkmark$ & 9 & $\Delta$ & f & $r$ & r & 1 & \\
\hline & & & & & & & & & & & & & & & & & & & & & - $/ \mathrm{Ar}$ & 1. عاطفه \\
\hline & & & & & & & & & & & & & & & & & & & & •/Ar &.$/ 94$ & r. كار آمدى \\
\hline & & & & & & & & & & & & & & & & & & & - /AF & $\cdot / v$ & $\cdot / V^{F}$ & ب. اهميت \\
\hline & & & & & & & & & & & & & & & & & & $\cdot / A r$ & .199 & $\cdot / 01$ & .194 & F. خود آينده \\
\hline & & & & & & & & & & & & & & & & & $\cdot / M$ & 每 & $-\cdot / 49$ & $-\cdot / T V$ & $-\cdot / 4 q$ & هـ خستخى \\
\hline & & & & & & & & & & & & & & & & $\cdot / \mathrm{AV}$ & $\cdot / N 1$ & $-\cdot / \mu 1$ & $-\cdot / F F$ &.$- / 49$ & $-\cdot / F q$ & 9. ناميدى \\
\hline & & & & & & & & & & & & & & & $\cdot / A 1$ & $\cdot / V^{F}$ & . /V9 & $-\cdot / Y V$ & $-\cdot / \kappa$ & $-\cdot / 4$. & $-\cdot / \& Y$ & V. عصبانيت \\
\hline & & & & & & & & & & & & & & $\cdot / V r$ & $\cdot / 91$ & .190 & $\cdot / \Delta F$ & $-\cdot / r$ & $-\cdot / r \wedge$ & $-\cdot / 4$. & - & ه اضطراب \\
\hline & & & & & & & & & & & & & $\cdot / T F$ & $-\cdot / \mu$ & $-\cdot / 49$ & $-\cdot / Y F$ & $-\cdot / \Upsilon \wedge$ & $\cdot / \mu \wedge$ & $\cdot / 4 T$ & . & $\cdot / \& \Delta$ & 9. لذت \\
\hline & & & & & & & & & & & & $\cdot / \mathrm{Vq}$ & $\cdot / \Delta \Lambda$ & $-\cdot / r Y$ & $-\cdot / 4 V$ &.$- / 01$ & $-\cdot / \Delta 1$ & $\cdot / A T$ & $\cdot / \Delta F$ & $\cdot / \Delta F$ & $\cdot / \Delta \Delta$ & ا. ا. غرور \\
\hline & & & & & & & & & & & $\cdot / \wedge$ & $\cdot / \Delta$ & ת & - & $-\cdot / r V$ & $-\cdot / 4$ & $-\cdot / 4 \Delta$ & $\cdot / f F$ & $\cdot / \Delta \mathrm{V}$ & .194 & $\cdot / 4 q$ & 11 إ. يامدهاى انتظار \\
\hline & & & & & & & & & & $\cdot / 9 r$ & $\cdot / \mathrm{V} q$ & $\cdot / \Delta r A$ & $\cdot / 41$ & $-\cdot / k r$ & $-\cdot / 4 \Delta$ &.$- / 49$ & $-\cdot / F r$ & $\cdot / 4 \Delta$ & $\cdot / 09$ & $\cdot / \mathrm{VI}$ & $\cdot / \Delta F$ & rا. انتظار كارآمدى \\
\hline & & & & & & & & &.$/ 91$ & .191 & $\cdot / 09$ & $\cdot / \Delta F$ & $\cdot / 4 \Delta$ & $-\cdot / r \Delta$ & $-\cdot / k r$ & $-\cdot / 49$ & $-\cdot / \Delta r$ & $\cdot / 9$ & .199 & $\cdot / 09$ & $\cdot / V F$ & זו. ارزش درونى \\
\hline & & & & & & & & $\cdot / A F$ & $\cdot 191$ & $\cdot / F V$ & $\cdot / 4 \mu$ & 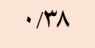 & $\cdot / \mu V$ & $-\cdot / r \Delta$ & $-\cdot /$ rq $^{4}$ & - & $-\cdot / 4 r$ & $\cdot / \Delta 9$ & $\cdot / \Delta r$ & $\cdot / 4$ & $\cdot / \Delta r$ & F أ. ارزش بيرونى \\
\hline & & & & & & & $\cdot / \wedge \mid$ & $\cdot / \Delta$ & $.19 \mathrm{~V}$ & $\cdot / 0$ & $\cdot / \Delta 9$ & $\cdot / 4 \Delta$ & 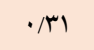 & $-\cdot / 19$ & - & $-\cdot / 4 q$ & $-\cdot / 49$ &.$/ 44$ & .194 & $\cdot / 01$ & $\cdot / 01$ & 1ها. ارزش كسب \\
\hline & & & & & & $\cdot / M$ & $-\cdot / Y F$ & $-\cdot / r q$ & $-\cdot / T V$ & - & $-\cdot / r \Delta$ & $-\cdot / T V$ & $-\cdot / T F$ & $\cdot / 4$ & $\cdot / 4 r$ & $\cdot / 4$ & $\cdot / \& V$ & $-\cdot / r 1$ & $-\cdot / \mu F$ & $-\cdot / \pi \Delta$ & $-\cdot / T V$ & 19. هزينه تلاش درونى \\
\hline & & & & &.$/ 91$ & .194 & $-\cdot / \pi$ & $-\cdot / 49$ & - - - & 每/ •- & $-\cdot / Y \Delta$ & $-\cdot / 49$ & $-\cdot / r \mid$ & $\cdot / 4$ & $\cdot / A r$ & $\cdot / A r$ & $\cdot / \& \Delta$ & $-\cdot / 19$ & $-\cdot / r$ & $-\cdot / r$ & $-\cdot / \mu F$ & Vا. از دست دادن فرصت \\
\hline & & & & $\cdot / 94$ & .190 & .190 &.$- / 14$ & - &.$- / 4 \Delta$ & $-\cdot / 4 \Lambda$ & $-\cdot / r^{4}$ & $-\cdot / 4 \mu$ & - - I I & $\cdot / \Delta F$ & $\cdot / \Delta \Delta$ & $\cdot / \Delta$ & $\cdot / \Delta \Delta$ & $-\cdot / 14$ & $-\cdot / 41$ & $-\cdot / 4 \pi$ & $-\cdot / \& V$ & 11. هزينه هيجانى \\
\hline & & & $\cdot / 9 F$ & $\cdot / \Delta \Lambda$ & $\cdot / \Delta r$ & $\cdot / \& \wedge$ & $-\cdot / r$ & $-\cdot / r \Delta$ & $-\cdot / r r$ & $-\cdot / r \Delta$ & $\cdot / \mathrm{TV}$ & $-\cdot / T V$ & $-\cdot / 19$ & $\cdot / 49$ & $\cdot|q|$ & $\cdot / / 9$ & $\cdot / 4 r$ & $-\cdot / 1 \wedge$ & $-\cdot / Y \Lambda$ & $-\cdot / Y \Lambda$ & $-\cdot / \pi$ & 19. هزينه تلاش بيرونى \\
\hline & & $\cdot / 49$ & $-\cdot / 49$ & $-\cdot / 49$ & $-\cdot / r \mu$ & $-\cdot / r r$ & $\cdot / r V$ & $\cdot / r \Lambda$ & $\cdot / r \wedge$ & $\cdot / \pi \Delta$ & $\cdot /$ / & $\cdot / r$. & $\cdot / r \Delta$ & $-\cdot / r$ & - ו ו & $-\cdot / r r$ & $-\cdot / 4 q$ & $\cdot / I V$ & $\cdot / r \Delta$ & $\cdot / \mathrm{rV}$ & $\cdot / 49$ & ·. ·. رفتارى \\
\hline & $\cdot / A F$ & $\cdot \pi \Delta$ & $-\cdot / \mathrm{IV}$ & $-\cdot / T \Delta$ & $-\cdot / 19$ & $-\cdot / Y Y$ & $\cdot / r \Delta$ & $\cdot / \pi \Delta$ & $\cdot / \mu \Lambda$ & $\cdot / r q$ & $\cdot / 49$ & $\cdot / \mu$ & $\cdot / \pi \Delta$ & $-\cdot / r$ & - & $-\cdot / r$ & $-\cdot / 4 \Delta$ & $\cdot / r F$ & . MFY & $\cdot / r \cdot 9$ & $\cdot / r V$ & II \\
\hline$\cdot / 90$ & $* * \cdot / \mu q$ & $\cdot|r|$ &.$- / 19$ & $-\cdot / I V$ & $-\cdot / I r$ &.$- / .9$ & ( & $\cdot / r \Lambda$ & $\cdot / \mu F$ & 每 & $\cdot / r v$ & 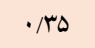 & $\cdot / r V$ & $-\cdot / 14$ & $-\cdot / Y \Delta$ & $-\cdot / 49$ & $-\cdot / Y \wedge$ & $\cdot / Y F$ & $\cdot / r V$ & $\cdot / 4$. & $\cdot / \mu F$ & r.r. شناختى \\
\hline $\mid F / F \Delta$ & $\mathrm{IV} / \cdot 1$ & $10 / A r$ & MNAY & $r r / 19$ & $19 / \cdot 4$ & $r \cdot / \mu r$ & Yr/QF & $19 / 19$ & $r 9 / 99$ & $Y \varphi / T Y$ & $r I / V q$ & Ir/Ar & $11 / 9$. & $1 . / 49$ & $9 / 4 \pi$ & $1 / 99$ & $9 / V 9$ & $\mid r / 11$ & $10 / 91$ & $\mid F / Y \Delta$ & $V / 90$ & ميانگين \\
\hline r/Ar & $\Delta / 4 q$ & $r / F \Lambda$ & $11 / \pi 9$ & $\mid N / \Delta \Delta$ & $11 / \cdot r$ & $\mid r / r$. & F/VG & $9 / 11$ & $\Lambda / \wedge$. & $V / \cdot 9$ & $4 / 91$ & $r / 9 \Lambda$ & $r / 9 T$ & $r / \Delta Q$ & r/AD & $F / \cdot F$ & $F / I F$ & $F / r q$ & $r / V r$ & $r / \Delta 9$ & $r / \cdot \Delta$ & انحر اف معيار \\
\hline
\end{tabular}


جدول "r. شاخص هاى برازش مدل معادله ساختارى

\begin{tabular}{|c|c|c|c|c|c|c|c|c|}
\hline AGFI & GFI & IFI & NFI & CFI & SRMR & RMSEA & $\chi^{Y / d f}$ & شاخص برازش \\
\hline$>\cdot / 9$ & $>\cdot / 9$ & $>\cdot / 9$ & $>\cdot / 9$ & $>. / 9$ & $<\cdot / \cdot \wedge$ & $<\cdot / \cdot \wedge$ & $\leq \Delta$ & مقدار مطلوب \\
\hline - /AND & ./А९৭ & $\cdot / 9.4$ & $\cdot / A \vee q$ & $\cdot / 9 . r$ & $\cdot 1 \cdot \sqrt{9}$ & ./.人 & F/FFq & مدل اوليه \\
\hline.$/ 9.1$ & $\cdot / 9 \cdot V$ &.$/ 91 r$ & $\cdot / M \Lambda V$ &.$/ 911$ & .1 .94 &.$/ \cdot v q$ & f/Ir. & مدل نهايى \\
\hline
\end{tabular}

برازش مطلوب مدل است. شاخصهاى GFI GCFI،IFI و NFI نيز از ملاكك مورد نظر (9/•) بزركتر هستند. ضرايب بدست آمده حاكى از برازش مطلوب مدل است.
در جدول ب شاخصهاى برازش مدل نهايى ارائه شده است. شاخص برازندگى ريشه واريانس خطاى تقريب (RMSEA) برابر V9• • • و ريشه استاندارد واريانس باقىمانده (SRMR) برابر با و (9) • است كه نشان دهنده

جدول ع. ضرايب مدل هاى اندازهزيرى در مدل معادله ساختارى يثوهش

\begin{tabular}{|c|c|c|c|c|c|c|}
\hline $\mathrm{P}$ & .C.R & ضرايب استاندارد & ضرايب غير استاندارد & & & \\
\hline & & $\cdot / A F$ & 1 & عاطفه & $\leftarrow$ & خودطرحو ارههاى رياضى \\
\hline$\cdot / \cdot 1$ & $r \cdot / r$. & $\cdot / \mathrm{v} \Lambda$ & $1 / 91$ & كار آمدى & $\leftarrow$ & خودطر حو ارههاى رياضى \\
\hline.$/ \cdot 1$ & $Y F / A G$ & $\cdot / \wedge 9$ & $1 / 91$ & اهميت & $\leftarrow$ & خودطرحو ارههاى رياضى \\
\hline \multirow[t]{2}{*}{$\cdot / \cdot 1$} & W/V. & $\cdot / N r$ & l/Ar & خود آينده & $\leftarrow$ & خودطرحوارههاى رياضى \\
\hline & & $\cdot / A F$ & 1 & 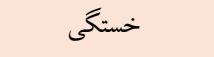 & $\leftarrow$ & حافظه منفى \\
\hline.$/ 1$ & $r r / q$. & $\cdot / \wedge \Delta$ & $\cdot / 99$ & 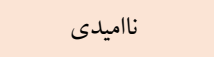 & $\leftarrow$ & حافظه منفى \\
\hline.$/ 1$ & YF/FF & ·/А &.$/ 91$ & عصبانيت & $\leftarrow$ & حافظه منفى \\
\hline \multirow[t]{2}{*}{.$/ \cdot 1$} & W/13 & $\cdot / N r$ & $\cdot / V \Delta$ & اضطراب & $\leftarrow$ & حافظه منفى \\
\hline & & $.19 \mathrm{~V}$ & 1 & ل لذت & $\leftarrow$ & حافظه مثبت \\
\hline \multirow[t]{2}{*}{.$/ \cdot 1$} & $\mid F / N$ & $\cdot / A F$ & $1 / \mathrm{VV}$ & غرور & $\leftarrow$ & حافظه مثبت \\
\hline & & $\cdot / 9 r$ & 1 & انتظار كار آمدى & $\leftarrow$ & باورهاى توانايى - انتظار رياضى \\
\hline \multirow[t]{2}{*}{.$/ 1$} & $r r / l q$ & $\cdot / \wedge \Delta$ & .191 & 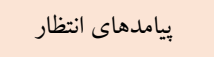 & $\leftarrow$ & باورهاى توانايى - انتظار رياضى \\
\hline & & $\cdot / 91$ & 1 & 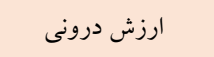 & $\leftarrow$ & ارزش تكليف رياضى \\
\hline.$/ 1$ & $19 / 1 r$ & $\cdot / V r$ & $\cdot / \Delta \Delta$ & ارزش بيرونى & $\leftarrow$ & ارزش تكليف رياضى \\
\hline \multirow[t]{2}{*}{.$/ \cdot 1$} & $19 / \Delta F$ & $\cdot / N r$ & $\cdot \operatorname{ser}$ & ارزش كسب & $\leftarrow$ & ارزش تكليف رياضى \\
\hline & & $\cdot / \mathrm{VV}$ & 1 & هزينه تلاش درونى & $\leftarrow$ & هزينه تكليف \\
\hline.$/ 1$ & $I V / M \Lambda$ & $\cdot / \mathrm{V} \wedge$ & $\cdot / 9$ & از دست دادن فرصت & $\leftarrow$ & هزينه تكليف \\
\hline.$/ 1$ & $1 N / 99$ & $\cdot / 19$ & $1 / 9 \mathrm{~V}$ & هزينه هيجانى & $\leftarrow$ & هزينه تكليف \\
\hline \multirow[t]{2}{*}{$\cdot / \cdot 1$} & $|F / \Delta|$ & .194 & $\cdot / \mathrm{Vq}$ & هزينه تلاش بيرونى & $\leftarrow$ & هزينه تكليف \\
\hline & & $\cdot / \Delta F$ & 1 & رفتارى & $\leftarrow$ & اشتياق رياضى \\
\hline.$/ \cdot 1$ & N/AV & .190 & $r / 9 V$ & عاطفى & $\leftarrow$ & اشتياق رياضى \\
\hline$\cdot / \cdot 1$ & $N / \Delta V$ & $\cdot / \Delta 9$ & $1 / N 1$ & شناختى & $\leftarrow$ & اشتياق رياضى \\
\hline
\end{tabular}

طر حوارههاى رياضى به صورت مستقيم بر باورهاى توانايى - انتظار رياضى

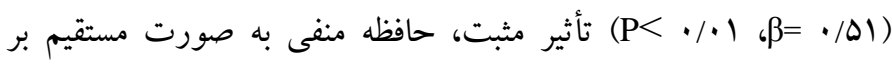
باورهاى توانايى - انتظار رياضى (F) حافظه مثبت به صورت مستقيم بر باورهاى توانايى - انتظار رياضى تأثير مثبت دارد. خودطرحوارههاى رياضى هم به
نتايج تحليل مدلهاى اندازه كيرى در جدول F ارائه شده است. معنىدار بودن وزنهاى رگر سيون مربوط به شش مدل اندازه گيرى نشانه معرف بودن همه شاخص هاى مورد استفاده براى متغيرهاى مكنون مربوطه است. در جدول ه ضرايب مربوط به اثرهاى مستقيم، غيرمستقيم وكل در مدل نهايى يثوهش ارائه شده است. بر اساس نتايج بدست آمده، خود 
ارزش تكليف رياضى تأثير دارد. باورهاى توانايى - انتظار رياضى نيز به صورت مستقيم (س//

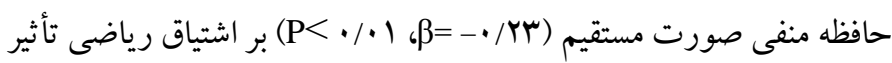

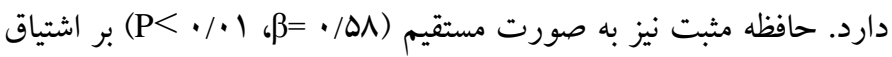
رياضى تأثير دارد. اثرات مستقيم حافظه عاطفى مثبت بر ارزش تكليف رياضى، رابطه مستقيم خودطرحوارههاى رياضى، ارزش تكليف رياضى و باورهاى توانايى - انتظار رياضى با اشتياق رياضى معنى دار نبود (ه •/ • > >).

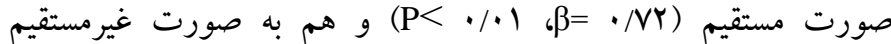

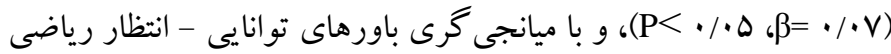
بر ارزش تكليف رياضى تأثير دارد. حافظه منفى هم به صورت مستقيم

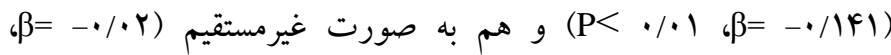
ه• • > P )، و با ميانجى كرى باورهاى توانايى - انتظار رياضى بر ارزش تكليف رياضى تأثير دارد. حافظه مثبت نيز تنها به صورت غيرمستقيم

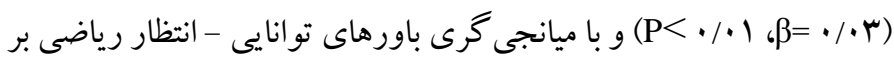

\begin{tabular}{|c|c|c|c|c|c|}
\hline واريانس تبيين شده & 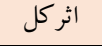 & اثرغيرمستقيم & اثرمستقيم & به متغير & 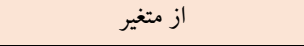 \\
\hline \multirow{3}{*}{$\cdot 191$} & $* * \cdot / 01$ & - & $* * . / \Delta 1$ & \multirow{3}{*}{ باورهاى توانايى - انتظار رياضى } & خودطرحو ارههاى رياضى \\
\hline & $*_{-} \cdot / f$ & - & $* *_{-\bullet / / F}$ & & حافظه منفى \\
\hline & $* * \cdot / r 1$ & - & $* * \cdot / r 1$ & & حافظه مثبت \\
\hline \multirow{4}{*}{$\cdot / A r$} & $* * \cdot / \mathrm{VA}$ & $* \cdot / \cdot v$ & $* * \cdot / V r$ & \multirow{4}{*}{ ارزش تكليف رياضى } & خودطر حو ارههاى رياضى \\
\hline & $*_{-} \cdot / 19$ & $*_{-\cdot / \cdot r}$ & $* *_{-} \cdot /$ If & & حافظه منفى \\
\hline & $* . / \cdot r$ & $* . / \cdot r$ & - & & حافظه مثبت \\
\hline & $* . / 1$ & - & $* . / / 4$ & & باورهاى توانايى - انتظار رياضى \\
\hline \multirow{2}{*}{$\cdot / \Delta F$} & $*_{-} \cdot / r \mu$ & - & $* *_{-} / r$ & \multirow{2}{*}{ اشتياق رياضى } & حافظه منفى \\
\hline & $* \cdot / \Delta \wedge$ & - & $* * \cdot / \Delta \Lambda$ & & حافظه مثبت \\
\hline
\end{tabular}

مسير اول نشان مى دهد خودطرحواره هاى رياضى بر ارزش تكليف رياضى با نقش واسطهاى باورهاى توانايى انتظار رياضى اثر ساختارى غيرمستقيم دارد. يافته هاى يزوهش حاضر همسو با بيزوهشهايى است كه خود طرحواره تحصيلى را نيز مانند ديكر خودطرحوارهها بهلحاظ ويز گیىهاى فردى در هويت تحصيلى فرد داراى اهميت مى دانند. به بيان ديكر، فردى كه در يادگيرى رياضى داراى خودطرحوارهُ مثبت است، قادر است به صراحت نشان دهد كه يادگيرى رياضى و تكاليف رياضى براى او اهميت

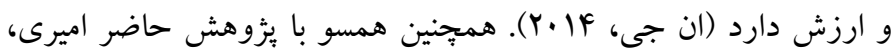
ابراهيمى و باباخانى (191/) دريافتند كه توانايى هاى شناختى بر اشتياق نحصيلى اثرمستقيم دارد. باورهاى توانايى - انتظار در دروس تحصيلى، انكيزش تحصيلى (ارزش درونى تكليف) را بيشبينى مى كند و بنابراين هنگامى كه تكليفى ارائه مىشود و فرد باورهاى توانايى - انتظار بالاترى دارد، انگيزش او براى آن تكليف برانگيخته مىشود و اين كونه است كه اهميت باورهاى توانايى - انتظار نشان داده مىشود (نيكولز، 19V9؛ به نقل
بحث و نتيجها Fيرى هدف اين مطالعه تدوين و اعتباريابى مدل ساختارى اشتياق رياضى، بر اساس خود -طر حواره هاى رياضى و حافظه عاطفى رياضى، با ميانجى گرى باورهاى توانايى - انتظار رياضى و ارزش تكليف رياضى بود. بر اين اساس مدلى طراحى شد كه حافظه عاطفى رياضى و خودطرحواره هاى رياضى به عنوان متغيرهاى برونزاد و باورهاى توانايى - انتظار رياضى و ارزش تكليف رياضى به عنوان متغيرهاى ميانجى، و اشتياق رياضى به عنوان بيامد در نظر كرفته شد.

يافته هاى اين مطالعه نه تنها ماهيت جندبعدى سازههاى نهفته را تأييد كرد بلكه نشان داد كه در بعضى از موارد اين سازهها ماهيت سلسله مراتبى دارند. اين مسير ها در سه دسته مى توان قرار داد كه عبارت است از:

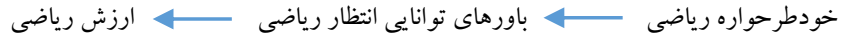

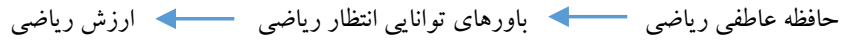

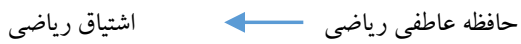


ارزشهاى اكتسابى اشاره مى كنند و تأثيرات مستقيم و غيرمستقيم (براى

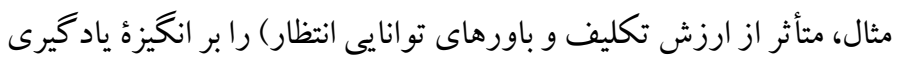

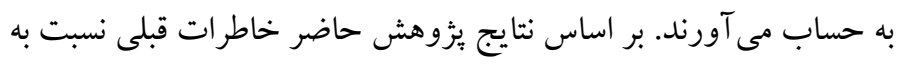

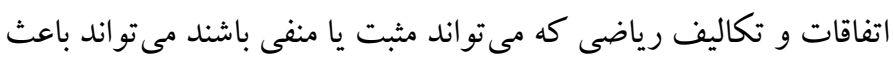

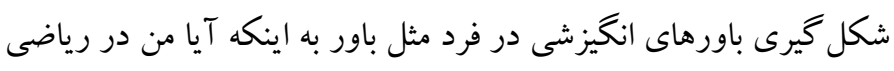

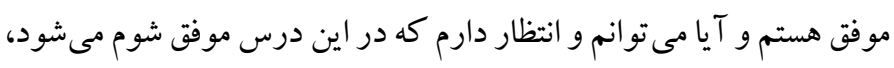
سبس اين باور توانيى انتظار فرد از خو در درس رياضى مبنايى مى وشود

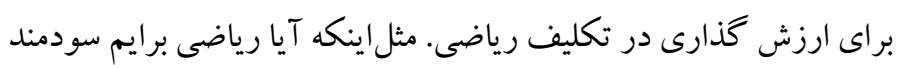

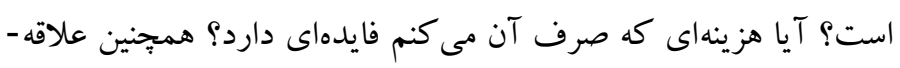

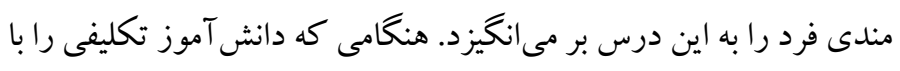

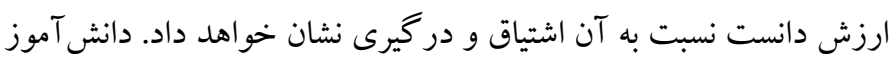
در اين درس سرمايه گذارى شناختى خو اهد كرد و علاقه و تمايل به انجام

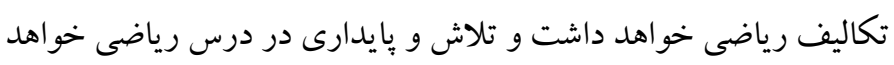
داشت. مسير سوم نشان داد حافظه منفى و حافظه مثبت نيز اثر ساختارى مستقيم بر اشتياق رياضى تأثير دارد. همجنين اثرات مستقيم خودطرحوارههاى رياضى، ارزش تكليف رياضى و باورهاى توانايى - انتظار رياضى بر اشتياق

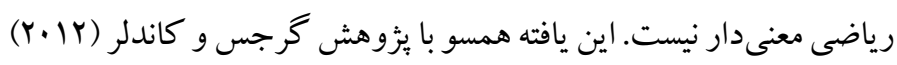

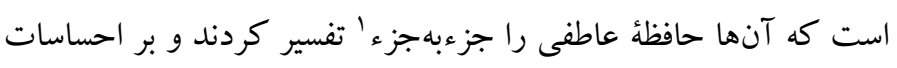

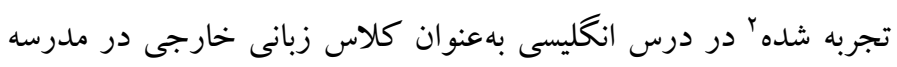

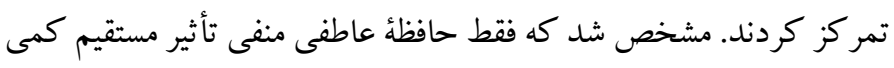
بر واكنش ويشبينىشده دانشآموزان نسبت به انخليسى بهمثابئ ابزار

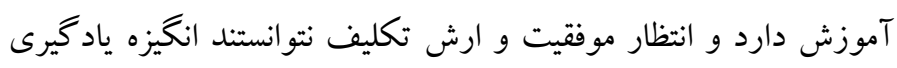

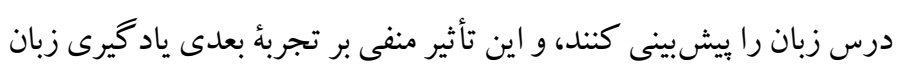

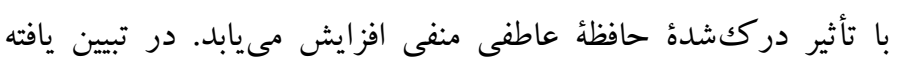

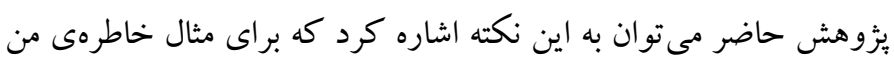

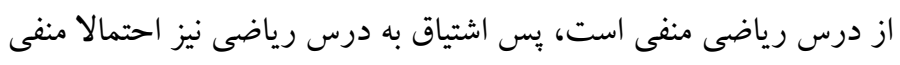

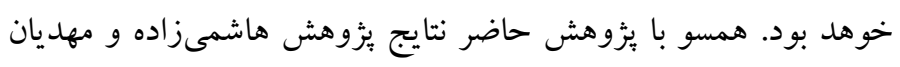

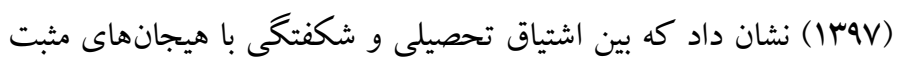

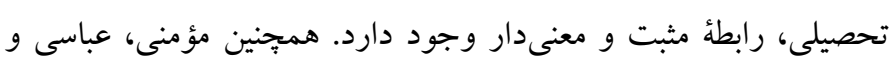

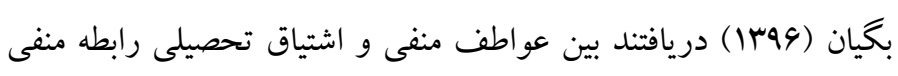

${ }^{2}$. emotions experienced

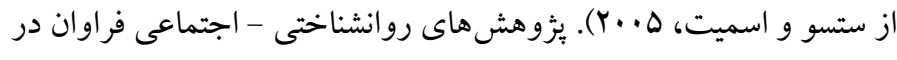

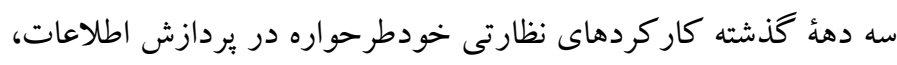

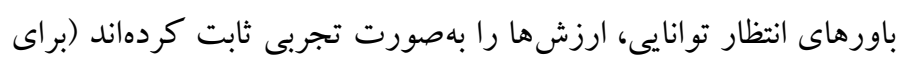

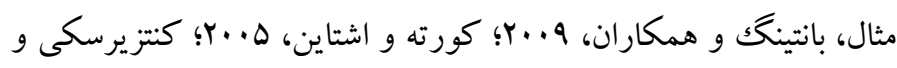

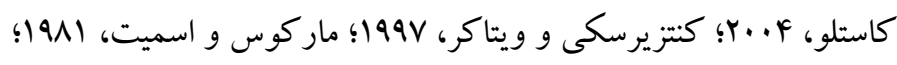

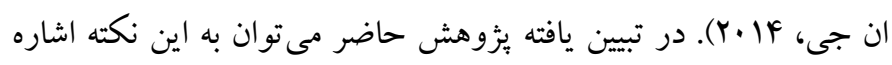

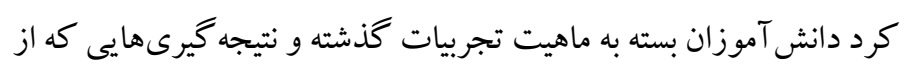
آنها مى كنند، ممكن است خودطرحوارهُ تحصيلى شامل علاقه يا ترس نسبت به دروس مختلف مدرسه براى خود ايجاد كنند. اين خود

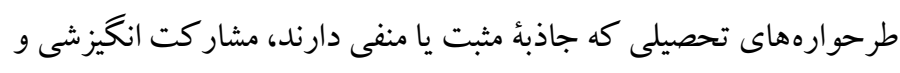

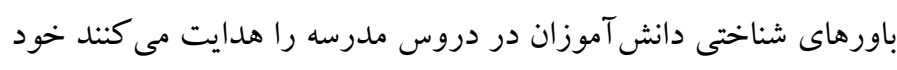
طرحواره علاوه بر اين كه بردازش اطلاعاتِ مربوط به خود را كنترل

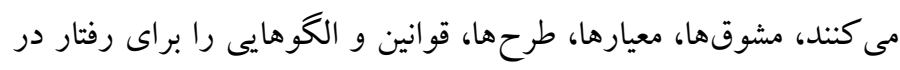

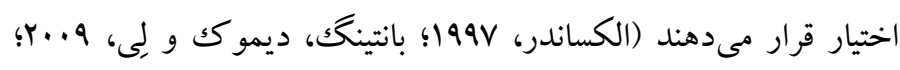

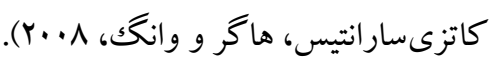

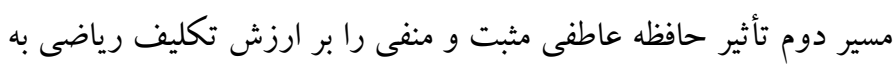

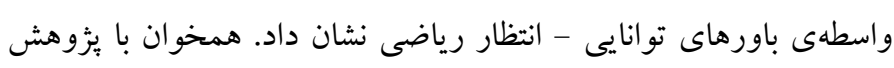

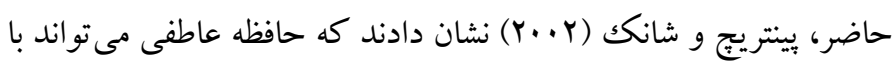

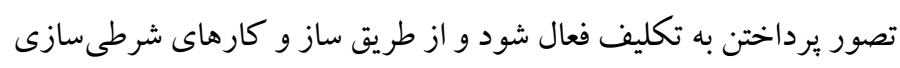

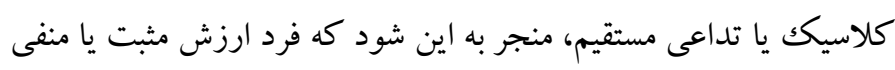

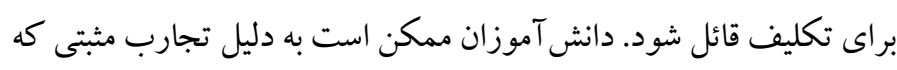
از درسى جون رياضى دارند، ارزش بيشترى براى اين درس قائل شوند و

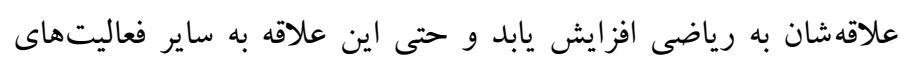

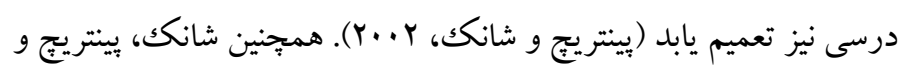

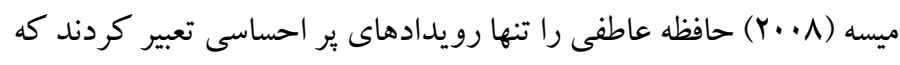
سالها بعد به خاطر سبرده مىشوند و همجينان بر رفتار و برداشتها

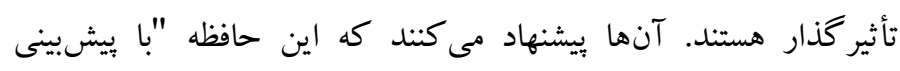
يرداختن به تكليف فعال مى شوند و ممكن است ازطريق شرطىسازى يا تداعى مستقيم، ارزش هاى مثبت يا منفى مختلفى براى آن تكليف به دنبال

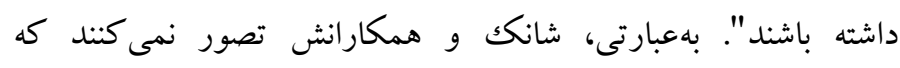

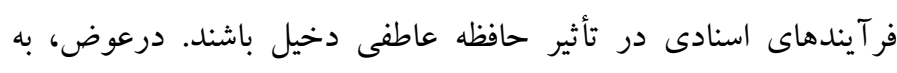

1 . interpreted 
از مفاهيم مختلف در فواصل زمانى مختلف انجام مى شود، روابط على بين سازههاى روانشناختى جند گانه را در الخوى ساختارى مفروض بيازمايند. همجنين در اين مطالعه از ابزارهاى اندازه گيرى خودگز ارشى استفاده شده

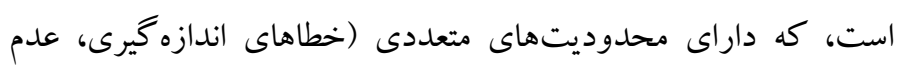
خويشتنزخرى شركت كنند كان) هستند. ازاينرو بيشنهاد مىشود كه از ديخر روش هاى جمع آورى دادهها استفاده شود تا شو اهدى از بسط يافته ها از يكك روش به روش ديكر فراهم كردد. در بزخوهش هاى آتى اثربخشى برنامههاى مداخلهاى مبتنى بر الكوى اين مطالعه در مدارس بررسى شود. ساير متغيرهاى بيامد و مرتبط با بيشرفت مىتواند در مطالعات آتى مورد توجه قرار كيرد. براى مثال، يافشارى، كوشش، انتخاب و رفتارهاى مرتبط

$$
\text { با بيشرفت مى تواند در مطالعات آتى بررسى شوند. }
$$

ملاحضات اخلاقى يّيروى از اصول اخلاق هُووهش: اين مقاله بركرفته از ر ساله دكترى نويسنده اول،

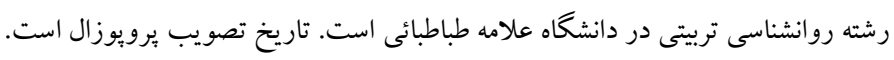

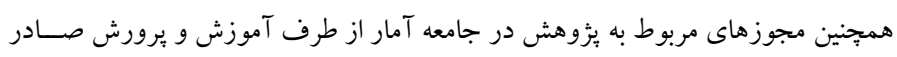

شده است.

حامى مالى: اين يزوهش در قالب رساله دكترى و بدون حمايت مالى مىباشد.

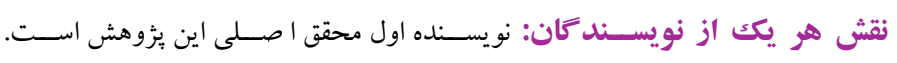

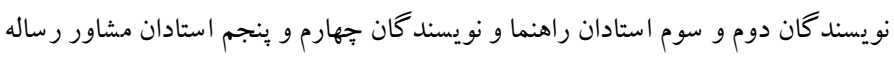

مىباشند. تضاد منافع: نو يسند كان هيج تضاد منافعى در رابطه با بثزوهش اعلام نمىنمايند.

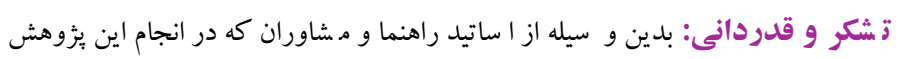
يارى نمودند قدردانى مى گردد.
وجود دارد. اين يافته مغاير با مبانى نظرى است كه به حافظه عاطفى بهعنوان مهم ترين عامل بيشبينى كنندهُ ارزش تكليف، جايگاه مهمى نسبت داده

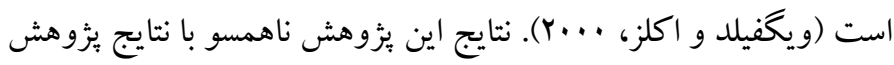

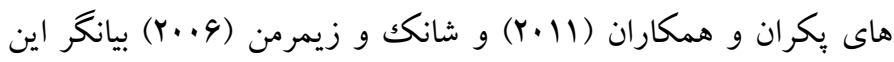
مطلب است كه، جِكونه و از جّه مسيرى ارزش تكليف مى تواند به عنوان متغير بيشبين، در تحقق متغير ملاكك دركيرى تحصيلى نقش داشته باشد كه، در اين خصوص از نقشهاى هيجانهاى بيشرفت و تأثير گذارى آنها

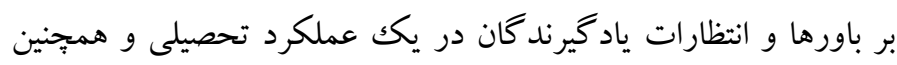
كسب راهبردهاى خودنظم جويى تحصيلى به عنوان مؤثرترين متغيرهاى واسطهاى براى تحقق بيشرفت تحصيلى مى توان نام برد و نيز ناهمسو با

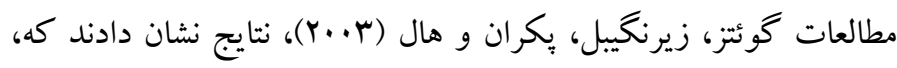
زمانى كه ارزيابى ارزش تكليف در سطح بالايى باشند، هيجان شادى و شوق و هيجان اميد در بالاترين حد خواهدبود يزوهش حاضر تلويحات نظرى و عملى جندى به همراه داشت. به لحاظ نظرى مدلى انكيزشى، شناختى و هيجانى براى اشتياق رياضى معرفى و در نمونه دانش آموزان ايرانى تأيد شد، كه به منابع مكتوب دربارهى اين سازه اضافه مىشود. همجنين به لحاظ كاربردى الكوهاى ساز كارى از اشتياق رياضى به دست آمد كه معلمين و مسئولان نظام آموزشى كشور مى توانند براى بهبود و ارتقاى اشتياق ياد گيرى دانش آموزان، از آنها استفاده كنند. مطالعه حاضر داراى ماهيتى مقطعى است. بنابراين، طرح استنتاجىهاى على و معلولى بر اساس يافته هاى آن براى محققان امكان يذير نمىباشد. براين اساس، به محققان علاقمند در اين قلمرو يثزوهشى بيشنهاد مى شود با استفاده از يكك طرح يزٔوهشى آينده نخر كه، در آن تمامى اندازه گيرىهاى به عمل آمده 


\section{References}

Abbasi, M., Dargahi, S., Pirani, Z., and Bonyadi, F. (2015). The role of procrastination and motivational self-regulation in predicting students' academic achievement. Iranian Journal of Medical Education, 15 (23), 160-169. (Persian). [Link]

Alexander, P. A. (1997). Knowledge-seeking and selfschema: A case for motivational dimensions of exposition. Educational Psychologist, 32, 83-94. [Link]

Amiri, L., Ebrahimi Moghadam, H., Babakhani, N. (2019). Structural model of predicting academic engagement based on cognitive ability and socioeconomic status mediated by academic motivation in students. Journal of Psychological Sciences, 18 (74), 215-222. (Persian). [Link]

Anderman, E. M., Eccles, J. S., Yoon, K. S., Roeser, R., Wigfield, A., \& Blumenfeld, P. (2001). Learning to Value Mathematics and Reading: Relations to Mastery and Performance-Oriented Instructional Practices .Contemporary Educational PsychologyVolume 26, Issue 1, 76-95. [Link]

Appleton, J.J., Christenson, S.L., Kim, D., \& Reschly, A.L. (2006). Measuring cognitive and psychological engagement: Validation of the student engagement instrument. Journal of School Psychology, 44, 427-445. [Link]

Archambault, I., Janosz, M. , Fallu, JS., \& Pagani, LS . (2009). Student engagement and its relationship with early high school dropout. Journal of adolescence, 32(3): 651-670. [Link]

Bakker, A. B., \& Demerouti, E. (2008). Towards a model of work engagement. Career development international. [Link]

Banting, L. K., Dimmock, J. A., \& Lay, B. S. (2009). The role of implicit and explicit components of exerciser self-schema in the prediction of exercise behaviour. Psychology of Sport \& Exercise, 10, 80-86. [Link]

Bowman, B. (2003). Cultural diversity and academic achievement, learning point. North Central Regional Educational Laboratory, 42(1): 12-20. [Link]

Carter, C. P., Reschly, A. L., Lovelace, M. D., Appleton, J. J., \& Thompson, D. (2012). Measuring student engagement among elementary students. Article in School Psychology Quarterly. 27(2):61-73. [Link]

Chatzisaranti, N. L., Hagger, M., \& Wang, J. (2008). "An experimental test of cognitive dissonance theory in the domain of physical exercise. Journal of Applied Sport Psychology, 20(1): 97-115. [Link]
Cook, D. A. \& Artino, A. R. (2016). Motivation to learn: an overview of contemporary theories. Medical education, 50(10): 997-1014. [Link]

Corte, C., \& Stein, K. F. (2005). Body-weight selfschema: Determinant of mood and behavior in women with an eating disorder1. Journal of Applied Social Psychology, 35, 1698-1718. [Link]

Eccles, J. S. (2005). Subjective task value and the Eccles et al. model of achievement-related choices. Handbook of competence and motivation, 105-121. [Link]

Eccles, J. S., et al. (1993). School and family effects on the ontogeny of children's interests, self-perceptions, and activity choices. Nebraska symposium on motivation, Lincoln, NE: U. Nebraska Press. [Link]

Eccles, J.S. (2009). Who am I and what am I going to do with my life? Personal and ability, family conflict, and developmental problems. Developmental Psychology, 49, 690-705. [Link]

Eklof, H. (2003). Test-taking Motivation on Low-Stakes Tests: A Swedish Timss (2003) Example. Department of Educational Measurement, mea university, Sweden. [Link]

Falahan, Z., Mahmoudnia, A., Ghaedi, Y., Zarghami, S. (1399). Explain how the cognitive elements of philosophical research affect the improvement of mathematical problem solving education. Journal of Psychological Sciences, 19 (90), 677-686. (Persian). [Link]

Flake, K.J., Barron, K.E., Hullman, C., Mccoach, B.D., $\&$ Welsh, M.E. (2015). The forgotten component of expectancy- value theory. Contemporary Educational Psychology, 41, 232-244. [Link]

Fredricks, J. A.; Blumenfeld, P. C. \& Paris, A. H. (2004). School Engagement: Potential of the Concept, state of the Evidence. Review of Educational research, 74(1), 59-109. [Link]

Fredricks, J.A., Blumenfeld, P., Friedel, J., \& Paris, A. (2005). School engagement. In K.A. Moore \& L. Lippman (Eds.), What do children need to flourish? Conceptualizing and measuring indicators of positive development.New York, NY: Springer Science and Business Media. 133-146. [Link]

Gao, Z. (2007). "Understanding students' motivation in physical education: integration of expectancy-value model and self-efficacy theory. Quest -IllinoisNational Association for Physical Education in Higher Education, 60(2):236-254. [Link]

Garcia, T. \& Pintrich, P. R. (1994). Regulating motivation and cognition in the classroom: The role of selfschemas and self-regulatory strategies. In D. H. 
Schunk \& B. H. Zimmerman (Eds.), Self-regulation of learning and performance: Issues and educational applications Hillsdale, NJ: Lawrence Erlbaum, 127-153. [Link]

Ghadmpour, E., Heidariani, L.., Barzgarbfrooi, M., Nasiri, H., Ghaffar, M., Raigani, M. (2018). The mediating role of activist memory and mathematical selfconcept in the relationship between mathematical anxiety and students' mathematical performance. Journal of Psychological Sciences, 18 (83), 22032211. (Persian). [Link]

Ghodsi, A., Talepasand, S., Rezaei, A. M., Mohammadifar, M. A. (2017). Psychometric properties of homework cost scale in high school students in Qom. Journal of Educational Measurement, 7 (28), 97-120. (Persian). [Link]

Gorges, J., \& Kandler, C. (2012). Adults' learning motivation: Expectancy of success, value, and the role of affective memories. Learning and Individual Differences, 22, 610-617. [Link]

Götz, T., Zirngibl, A., Pekrun, R., \& Hall, N. (2003) Emotions, learning and achievement from an educational-psychological perspective. In: MAYRING, Philipp, ed., Christoph VON RHOENECK, ed. Learning emotions: the influence of affective factors on classroom learning. Frankfurt am Main:Peter Lang, 9-28. ISBN 3-631-39903-0. [Link]

Hashemizadeh Nahi, N., Mehdian, H. (2018). The role of academic enthusiasm and flourishing in predicting students' academic excitement. Journal of Educational Psychology Studies, 31 (15), 243-270. (Persian). [Link]

Hobfoll, S.E., Johnson, R.J., Ennis, N., \& Jackson, A.P. (2003). Resource loss, resource gain, and emotional outcomes among inner city women. Journal of Personality and Social Psychology, 84(3): 632-643. [Link]

Hosseini, F. S., Talepasand, S., Bigdeli, I. (2010). The role of expectation-value components in the development of chemistry. Educational psychology. Allameh Tabatabai University, 18 (6), 69-39. (Persian). [Link]

Hotaman, D. and F. Yüksel-Sahin (2010). The Effect of Instructors' Enthusiasm on University Students' Level of Achievement Motivation. Egitim ve Bilim 35(155): 89. [Link]

Jacob, J.E., Lanza, S., Osgood, D.W., Eccles, J.S. \& Wigfield, A. (2002). Changes in Children's SelfCompetence and Values: Gender and Domain
Differences across Grades One through Twelve', Child Development, 2, 509-27. [Link]

Kendzierski, D., \& Costello, M. C. (2004). Healthy eating self-schema and nutrition behavior. Journal of Applied Social Psychology, 34, 2437-2451. [Link]

Kendzierski, D., \& Whitaker, D. J. (1997). The role of self-schema in linking intentions and behavior. Personality and Social Psychology Bulletin, 23, 139-147. [Link]

Knowles, M, S., Holton, E, F., \& Swanson, R, A. (2005). The adult learner: the definitive classic. Adult Education and Human Resource Development [ebook]. Amsterdam: Routledge. [Link]

Lazarides, R., Gaspard, H., \& Dicke, A.-L. (2018). Dynamics of classroom motivation: Teacher enthusiasm and the development of math interest and teacher support. Learning and Instruction. [Link]

Linnenbrink, E. A. (2006). Emotion research in education: Theoretical and methodological perspectives on the integration of affect, motivation, and cognition. Educational Psychology Review, 18, 307-314. [Link]

Linnenbrink, L, G., Pekrun, R. (2011). Students' emotions and academic engagement: Introduction to the special issue. Contemporary Educational Psychology. 36-1-3. [Link]

Markus, H. (1977). Self-schemata and processing information about the self. Journal of Personality and Social Psychology, 35(2), 63-78. [Link]

Martin, A. J., Way, J., Bobis, J. \& Anderson, J. (2015). Exploring the ups and downs of math engagement in the middle school years. Journal of Early Adolescence, 35, 199-244. [Link]

Matusovich, H., Streveler, R., Loshbaugh, H., Miller, R., \&. Olds, B. (2008). Will I Succeed in Engineering? Using Expectancy-Value Theory in a Longitudinal Investigation of Students' Beliefs. Center for the Advancement of Engineering Education. ASEE 2008 Annual Conference: 22-25. [Link]

Momeni, K., Abbasi, M., Pirani, Z., Begian Koleh Marz, J. (2017). The role of family excitement and emotional atmosphere in predicting students' academic achievement. Cognitive Strategies in Learning, 5 (8) 159-182. (Persian). [Link]

Ng, C. \& Renshaw, P. (2002). Self-schema, motivation and learning: A cross-cultural comparison. Research on sociocultural influences on motivation and learning, 2, 55-87. [Link]

Ng, C.-h. C. (2014). Examining the Self-Congruent Engagement Hypothesis: The Link between 
Academic Self-Schemas, Motivational Goals, Learning Approaches and Achievement within an Academic Year. Educational Psychology. 34(6), 730-762. [Link]

$\mathrm{Ng}$, C-h. (2005a). Academic self-schemas and contrasting self-congruent learning patterns: Findings validated with culturally different samples. Social Psychology of Education, 8, 303-328. [Link]

$\mathrm{Ng}$, C-h. (2005b). Modelling the relationships between self-schemas, learning and learning outcomes in the domain of high school mathematics. Psychologia, 48 (1), pp. 14-30. [Link]

Nosek, B, A., \& Smyth, F, L. (2011). Implicit social cognitions predict sex differences in math engagement and achievement. American educational research journal, 48(5), 1125-1156. [Link]

Patricia, A, N. (2000). Cost Perception and the Expectancy-Value Model of Achievement Motivation. Paper Presented at The Annual Meeting of the American Educational Research Association (New Orleans, La; 21-28, 2008. [Link]

Pekrun, R., Goetz, T., Titz, W., \& Perry, R. P. (2002). Academic emotions in students' self-regulated learning and achievement: A program of qualitative and quantitative research. Educational Psychologist, 37, 91-105. [Link]

Pekrun, R., Vom H, R., Blum, W., Frenzel, A, C., Goetz, T., \& Wartha, S. (2007). Development of mathematical competencies in adolescence: The PALMA longitudinal study. [Link]

Pekrun, R.; Goetz, T.; Frenzel, A. C.; Barchfeld, P.; Perry, R. P. (2011).measuring emotions in students' learning and performance: Theachievement emotions questionnaire (AEQ). Contemporary Educational Psychology, 36(1), 36-48. [Link]

Pillemer, D. B. (1998). Momentous events, vivid memories. London: Harvard University Press. [Link]

Pillemer, D. B. (2001). Momentous events and the life story. Review of General Psychology, [Link]

Pintrich, P. and D. Schunk (2002). The role of goals and goal orientation. Motivation in education: Theory, research, and applications, 2, 190-242 [Link]

Safari, H., Janaabadi, H., Amir Abbasi, M. (2015). Predicting academic motivation based on spiritual intelligence and psychological toughness. Journal of Education Strategies in Medical Sciences, 8 (6), 7-12. (Persian). [Link]
Schunk, D. H., Pintrich, P. R., \& Meece, J. L. (2008). Motivation in education: Theory, research, and applications. Englewood Cliffs, NJ: Merrill. [Link]

Schunk, D. H., Pintrich, P. R., \& Meece, J. L. (2008). Motivation and control beliefs: Distinguishing the means and ends. In P. A. Alexander \& P. H. Winne (Eds.), Handbook of Educational Psychology (2nd ed., pp. 349- 367). Mahwah, NJ: LEA. [Link]

Schutz, P. A., \& Lanehart, S. L. (2002). Introduction: Emotions in education. Educational Psychologist, 37, 67-68. [Link]

Setsuo, O., Smith, I., D. (2005). Educational applications of the expectancy value model of achievement motivation. in the drivers cultural contexts of the west and est. CHANOE:TRANSFORMATIONS IN EDUCATION,VOLUME 8.1. [Link]

Simpkins, D. S., \& Davis-Kean, E. P. (2005). The Intersection between Self-Concepts and Values: Links between Beliefs and Choices in High School. Jacobs, E. J, Simpkins, D. S.Leaks in the Pipeline to Math, Science and Technology Careers. [Link]

Trowler, V. (2010). Student engagement literature review. Department of Educational Research Lancaster University. The Higher Education Academy. [Link]

Wang, M. T., \& Eccles, J. S. (2013). School context, achievement motivation, and academic engagement: A longitudinal study of school engagement using a multidimensional perspective. Learning and Instruction, 28, 12-23. [Link]

Wang, M. T., \& Holcombe, R. (2010). Adolescents' Perceptions of School Environment, Engagement, and Academic Achievement in Middle School. American Educational Research Journal, 47, 633662. [Link]

Wang, M. T., Fredricks, A., Ye, J., Hofkens, F., Linn, T, L., \& Schall, J. (2016). The math and science engagement scales: Scale development, validation, and psychometric properties. Learning and Instruction, 43, 16-26. [Link]

Wang, z. (2008). academic motivation, mathematics Achievement, and The School Context: Building Achievement Models Using Timss2003.Adissertation Precedent to The Faculty of The Graduate School at The University of Missouri. [Link]

Wang, Z., Willett., A., \& Eccles, J. S. (2011). The assessment of school engagement: Examining dimensionality and measurement Wang, Ming-Te Willett, John B Eccles, Jacquelynne S invariance by gender and race/ethnicity. Journal of School Psychology, 49(4): 465-480. [Link] 
Wang, ze. (2008). academic motivation, matematics Achivement, and The School Context: Bulding Achivement Models Using Timss2003.Adissertation Presedent to The Faculty of The Graduate School at The University of Missoari. [Link]

Watt, H. M. G., Eccles, J. S., \& Durik, A. M. (2006). The leaky mathematics pipeline for girls: A motivational analysis of high school enrolments in Australia and the USA. Equal Opportunities International, 25, 642-659. [Link]

Weiner, B. (1992). Human motivation: Metaphors, theories, and research. Newbury Park, CA: Sage. [Link]

Welch Deal, M. R. (2003). Gender differences in expectancy of academic success in mathematics. The Graduate School University of WisconsinStout. Submitted in Partial Fulfillment of the Requirements for the Master of Science Degree with a Major in Guidance and Counseling. [Link]

Wigfield, A. \& Eccles, J., S. (2000). Expectancy-value theory of achievement motivation. Contemporary Educational Psychology, 25(1), 68-81. [Link]

Wigfield, A. \& Eccles, J., S. (2002). development of achievement motivation. In book: Handbook of Child Psychology and Developmental Science, 144. [Link]

Wigfield, A., Burnes. J.P., Eccles J.S. (2006). Development during Early and Middle adolescence. (Chapter 5). Hand book of Educational Psychology. Second Edition, Edited by Alexander P. A; winne, P.H.Lawernce Erlbaum Associates, Publishers, Mahwah, New Jersey, London. [Link]

Wigfield, A., Stephen, T., \& Susan Lutz, K.. (2009). Expectancy-value theory. Handbook of motivation at school, 55-75. [Link]

Wigfield, A., Tonks, S., \& Eccles, J., S. (2004). Expectancy-value theory in cross-cultural perspective. In D. M. McInerney \& S. Van Etten (Eds.), Big theories revisited, 165-198. [Link]

Yarahmadi, Y., Naderi, N., Akbari, M., Yaqubi, A. (2019). The effectiveness of an educational program based on academic resilience in academic procrastination and students' academic performance. Journal of Teaching Research, 1 (7), 233-249. (Persian). [Link]

You, S., \& Sharkey, J. (2009). Testing a developmentalecological model of student engagement: A multilevel latent growth curve analysis. Educational Psychology, 29, 659-684. [Link]
Zhang, Q. (2013). Assessing the Effects of Instructor Enthusiasm on Classroom Engagement, Learning Goal Orientation, and Academic Self-Efficacy. Communication Teacher, 28(1), 44-56. [Link] 